\title{
Potential of Stem Cells in the Treatment of Nervous System Disorders
}

\author{
Masoumeh Seghatoleslam ${ }^{1}$, Mahmoud Hosseini ${ }^{2,3,4^{*}}$ \\ ${ }^{1}$ Department of Anatomy and Cell Biology, School of Medicine, Mashhad University of Medical Sciences, Mashhad, Iran. \\ ${ }^{2}$ Neurocognitive Research Center, School of Medicine, Mashhad University of Medical Sciences, Mashhad, Iran. \\ ${ }^{3}$ Neurogenic Inflammation Research Center, School of Medicine, Mashhad University of Medical Sciences, Mashhad, Iran. \\ ${ }^{4}$ Department of Physiology, School of Medicine, Mashhad University of Medical Sciences, Mashhad, Iran.
}

\section{A BSTRACT}

Introduction: The stem cells are undifferentiated cells that have a potential to produce many different cell types in the body. A vast amount of data indicates the potential of stem cell therapy for various neurological diseases. In the present review, the possible beneficial effects of stem cells for treatment of nervous system disorders were presented. The stem cells have been suggested for treatment of different acute and chronic nervous system disorders such as hemorrhagic as well as ischemic stroke, Parkinson's disease, Hantington's disease, amyotrophic lateral sclerosis, multiple sclerosis, and Alzheimer's disease. Conclusion: Stem cells have been frequently examined in experimental studies and may be considered as the new developing strategies to treat nervous system disorders in the near future.

* Corresponding Author: Mahmoud Hosseini

E-mail: hosseinim@mums.ac.ir 
توانايى سلولهاى بنيادى در درمان بيمارى هاى سيستهم عصبى

معصومه ثقة الاسلام'، سيد محمود حسينى Fr.F.F

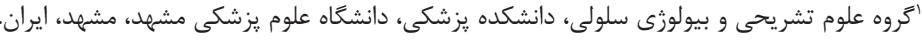

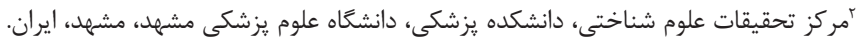

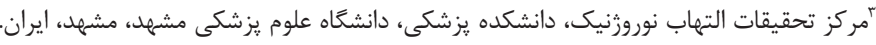

|

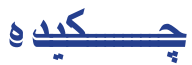

مقدمه: سلولهاى بنيادى سلولهاى تمايزنيافتهاى هستند كه توانايى توليد انواع مختلفى از سلولها را

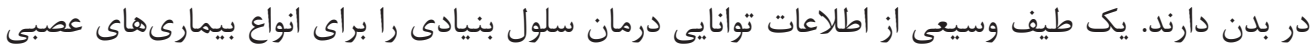

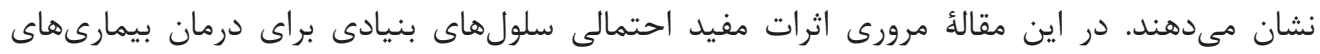

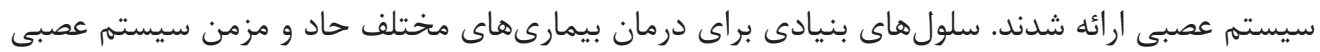

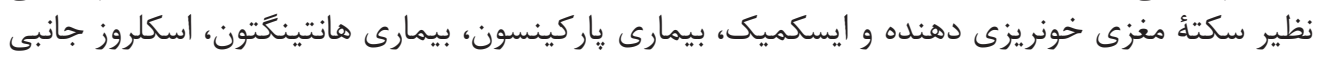

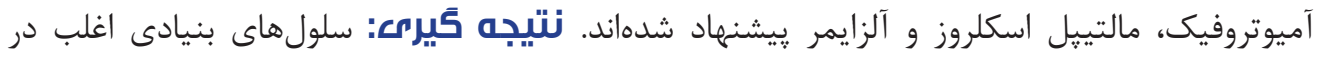

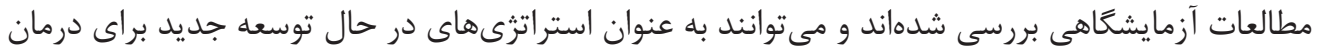

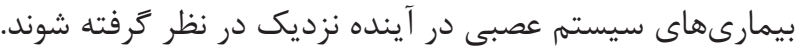

كليد وازهها:

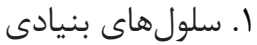

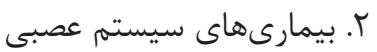

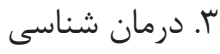


ممكن است در درمان بيمارىهاى عصبى ذكر شده مفيد باشند.

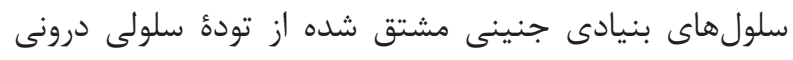

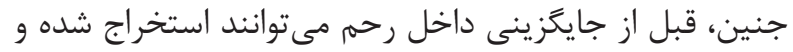

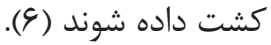

در نواحى خاصى از مغز يستانداران بالغ نظير ناحيةٌ تحت بطنى

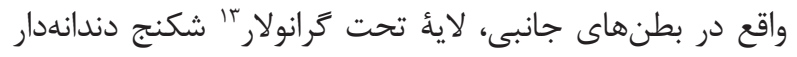

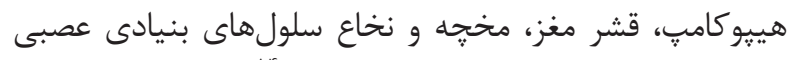

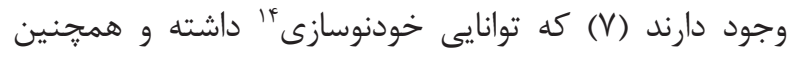

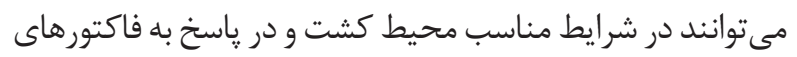

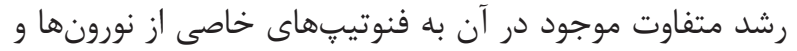

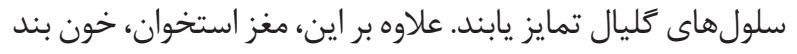

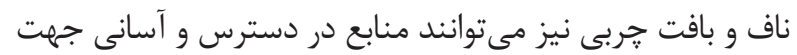

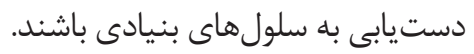

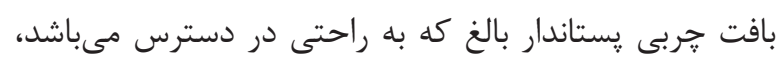

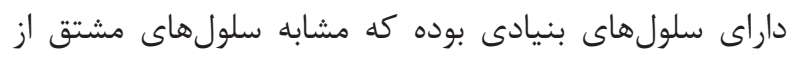

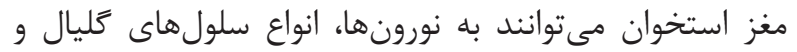

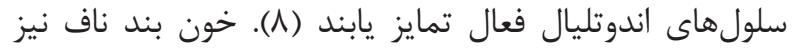

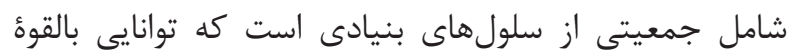

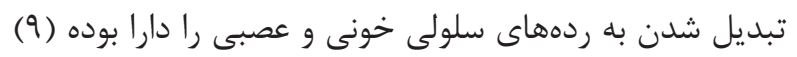

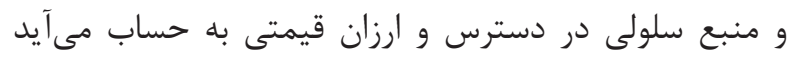

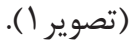

\author{
سلول هاى بنيادى و بافت عصبى
}

سلولهاى بنيادى سلولهاى تمايزنيافتهاى هستند كه توانايى

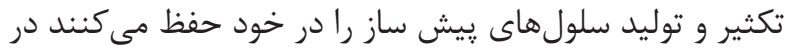

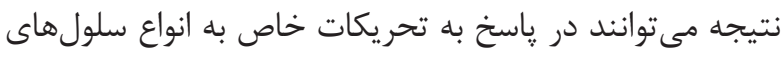

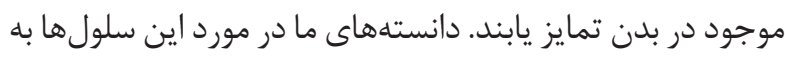

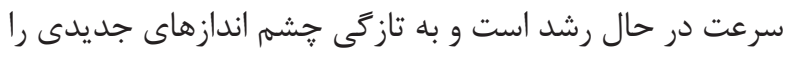

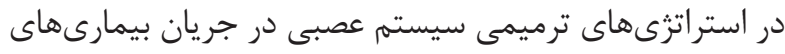

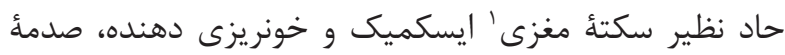

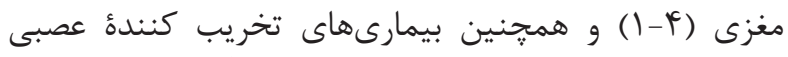

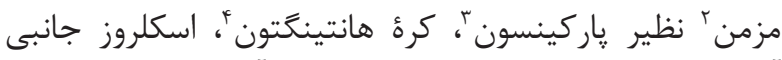

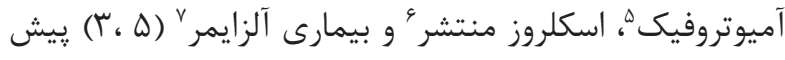
روى ما گذاشته است.

سلول درمانى ^يك استراتثى جالب و مؤثر در درمان بيمارىهاى

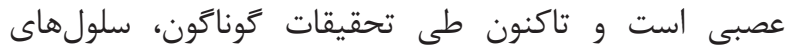

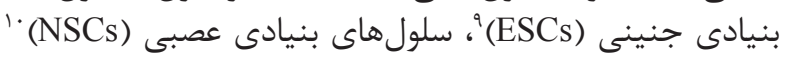

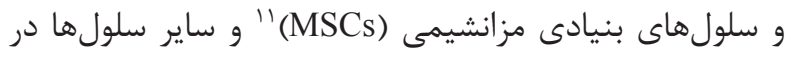
درمان بيمارىهاى عصبى به كار رفتهاند (نمودار ()). سلولهاى بنيادى متنوعى در سرتاسر دوره تكامل يستانداران

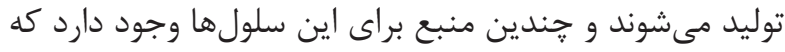
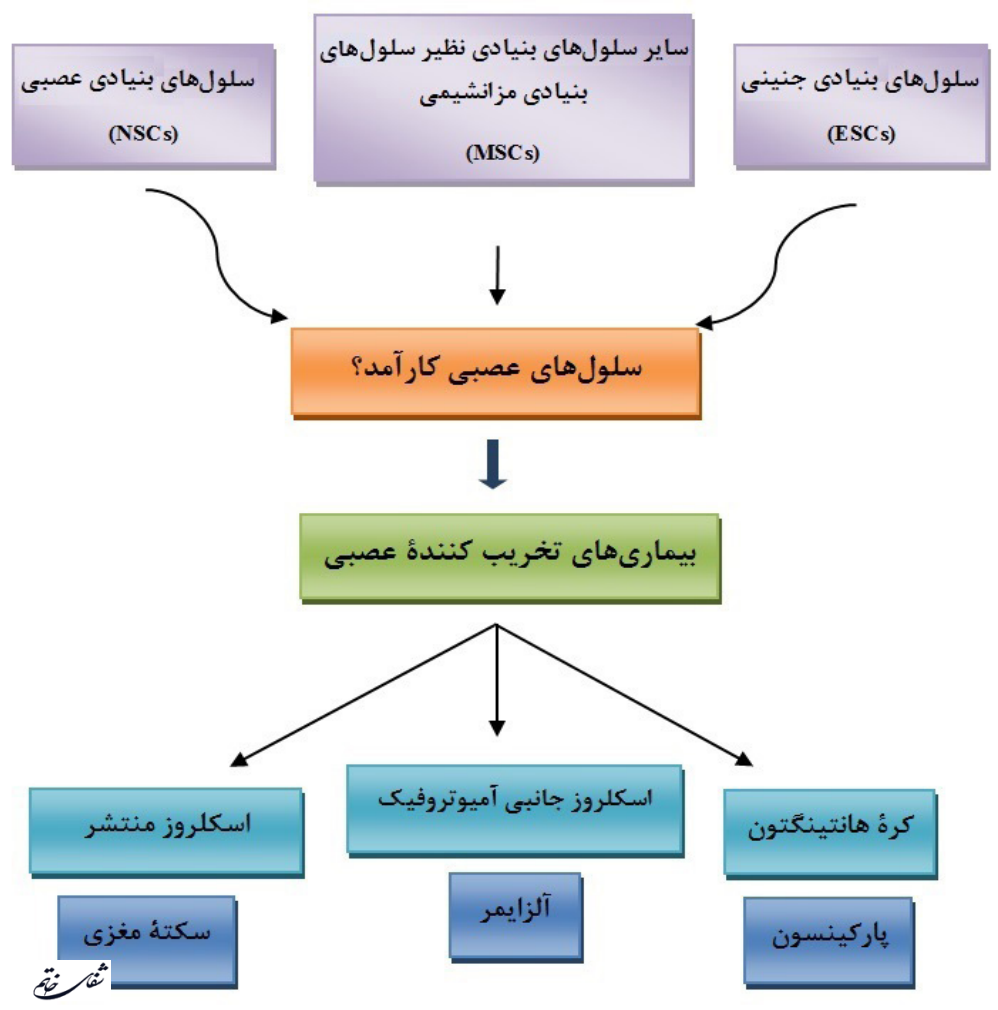

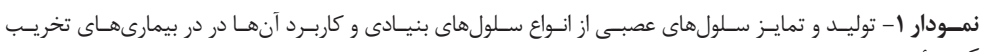

\section{${ }^{1}$ Stroke}

${ }^{2}$ Chronic neurodegenerative disease

${ }^{3}$ Parkinson's disease (PD)

${ }^{4}$ Huntington's Chorea disease (HD)

${ }^{5}$ Amyotrophic lateral sclerosis (ALS)

${ }^{6}$ Multiple sclerosis (MS)

${ }^{7}$ Alzheimer disease (AD)
${ }^{8}$ Cell therapy

${ }^{9}$ Embryonic stem cells (ESCs)

${ }^{10}$ Neural stem cells (NSCs)

${ }^{11}$ Mesenchymal stem cells (MSCs)

${ }^{12}$ Subventricular zone

${ }^{13}$ Subgranular layer

${ }^{14}$ Self-renewal 


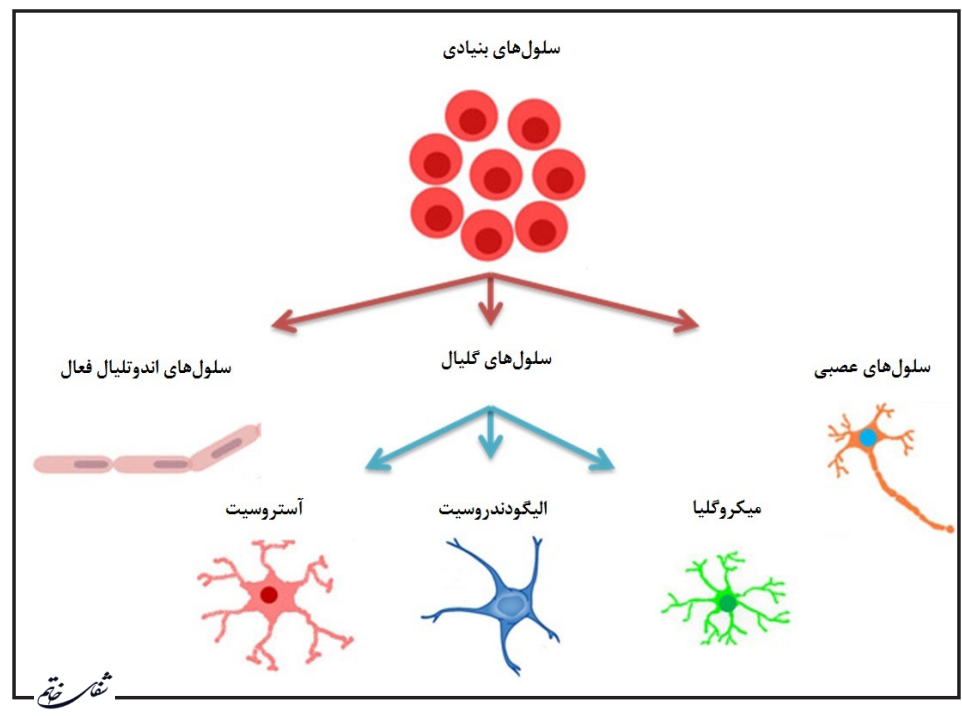

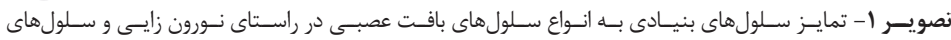

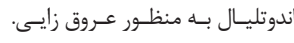

اختلال در بلع و سخن كفتن ظاهر مى گردد. پاتولوزى اصلى در اين بيمارى، تخريب و دزنره شدن نورونهاى

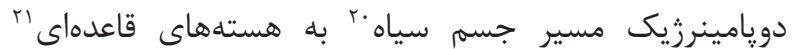
مغز مىباشد و رايجترين روش درمانيك دانى اين بيمارى استفاده از

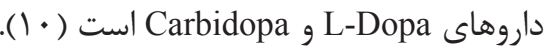
در واقع اين دو ماده كه سبب افزايش ساخت و رها رها سازى

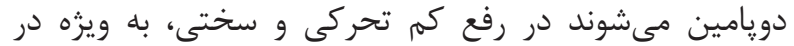

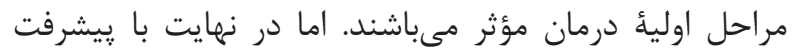

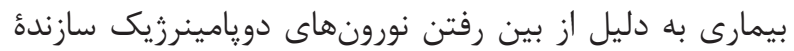

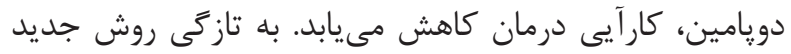

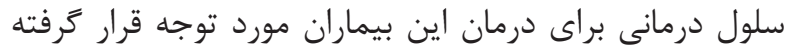

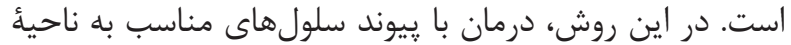

$$
\text { آسيب ديده صورت مى ديرد (تصوير ك). }
$$

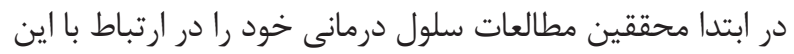

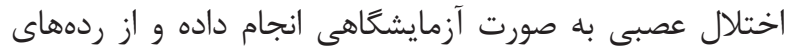

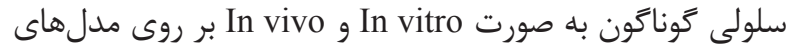

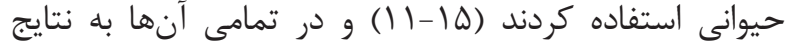

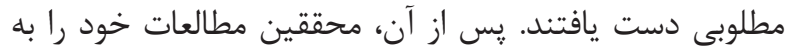

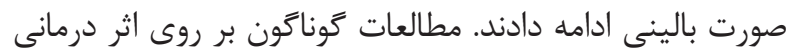

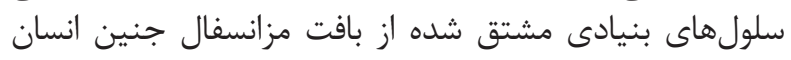

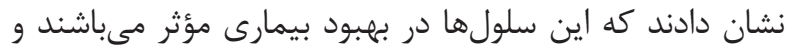

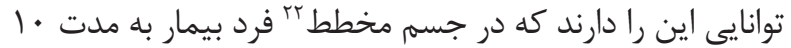

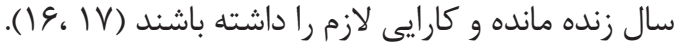
اين سلولهاى ييوند شده قادر بودند دويامين ترشح كنيند و

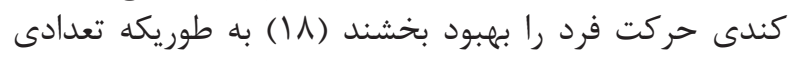

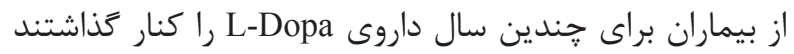

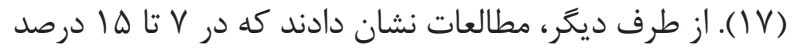

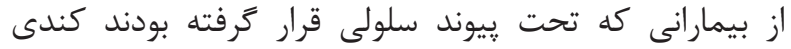

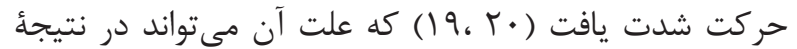

\section{${ }^{15}$ Forebrain}

${ }^{16}$ Bradykinesia

${ }^{17}$ Rigidity

${ }^{18}$ Tremor

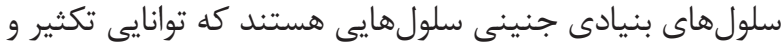

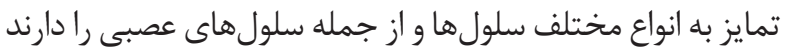

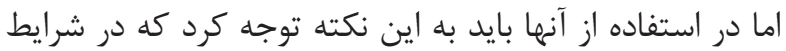

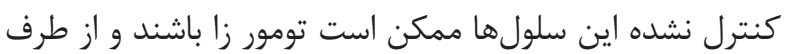

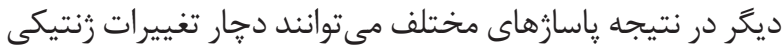

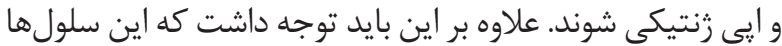
ممكن است بوسيله سيستم ايمنى يس زئ زده شوند.

سلولهاى بنيادى عصبى جزء سلولهاى بنيادى بالغى هستند

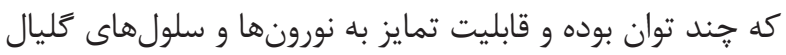

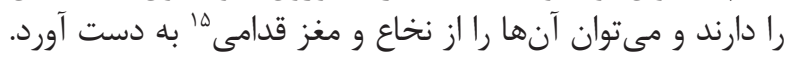

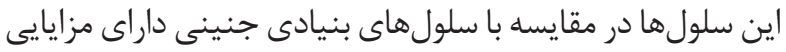

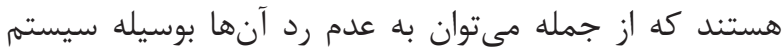

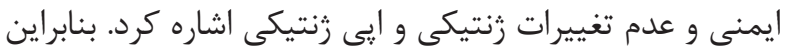

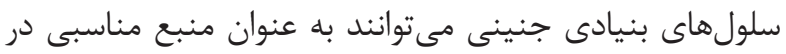

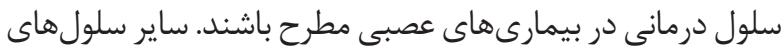

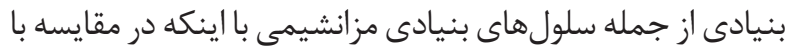

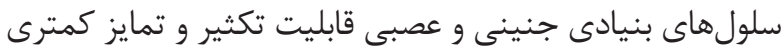

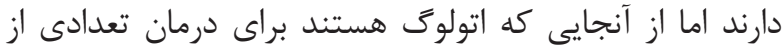
بيمارى هاى عصبى مورد توجه ويزه قرار كرفتئهاند.

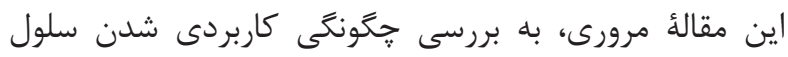

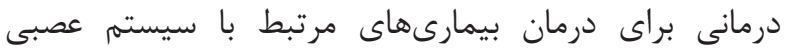

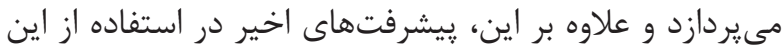

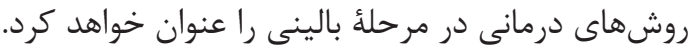
آيا سلول درمانى در بيماران مبتلا به هاركينسون مؤثر

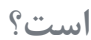

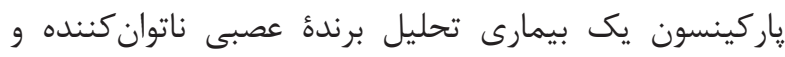

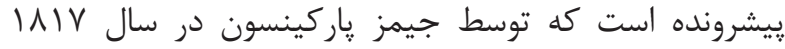

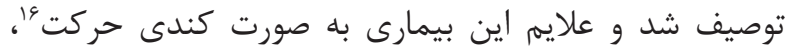

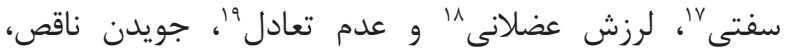

${ }^{19}$ Postural instability

${ }^{20}$ Substantia Nigra

${ }^{21}$ Basal ganglia

${ }^{22}$ Striatum 


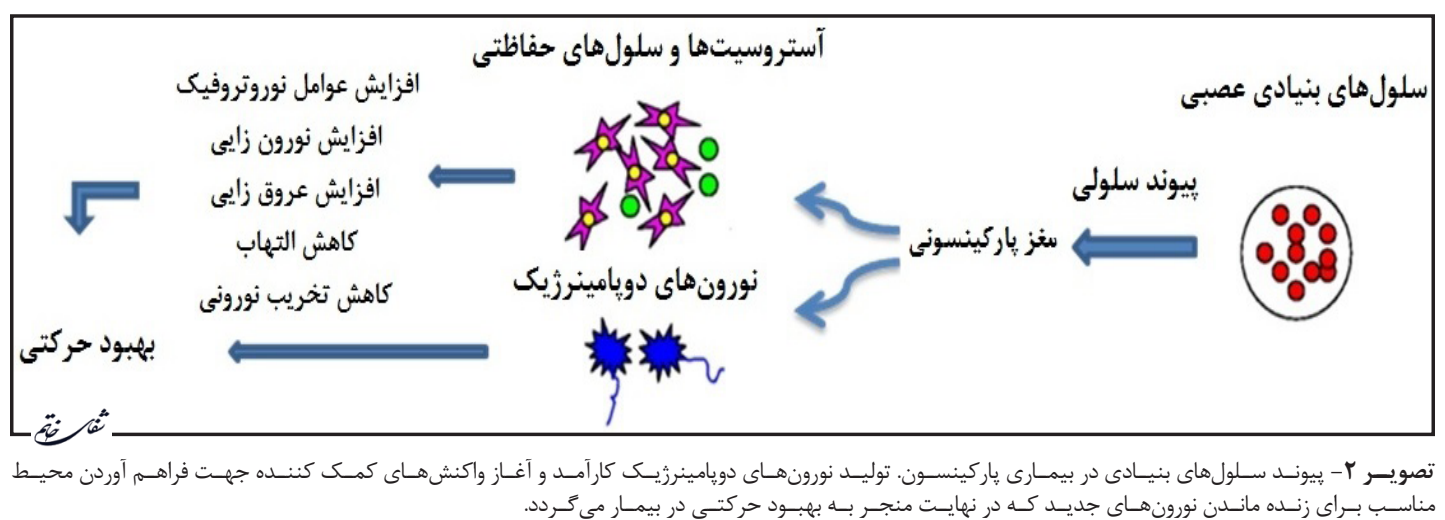

كمك تكنولورى فرآورى سلولهاى بنيادى بتوان مقدار زيادى

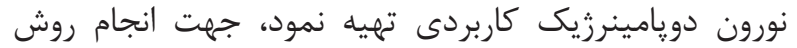

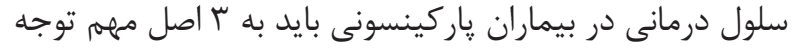

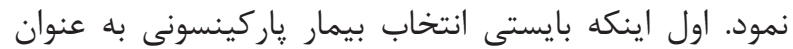

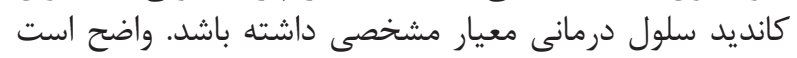

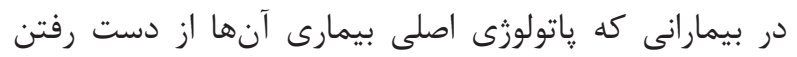

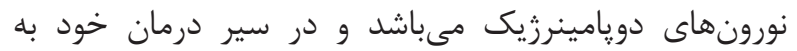

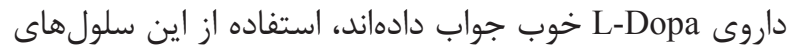

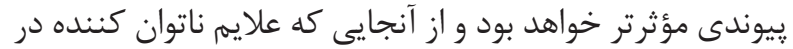

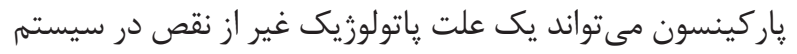

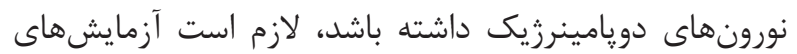

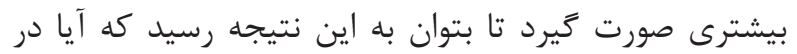

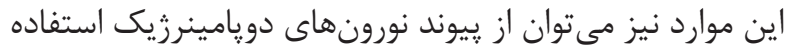

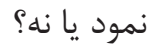

دوم اينكه ميزان سودمندى سلول هاى ييوندى بايستى گَيسترش

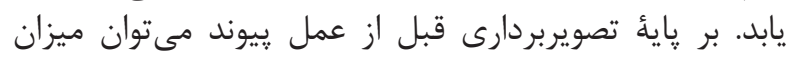

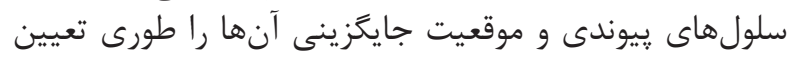

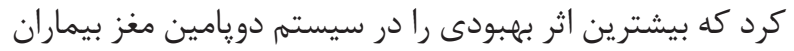

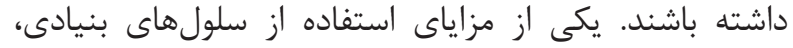

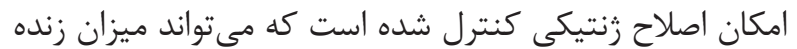

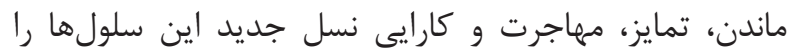

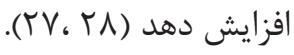
جهت بازگشت علايم ياركينسون به حالت طبيعى، تحريك رشد

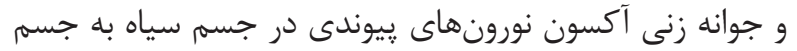

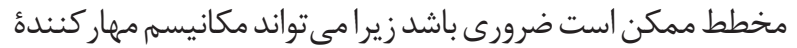

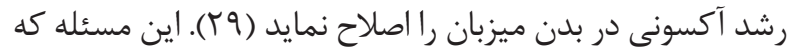

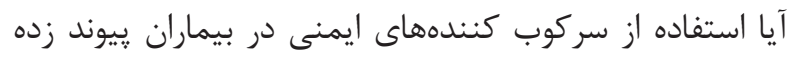

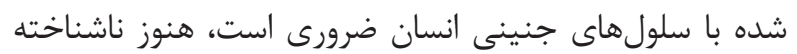

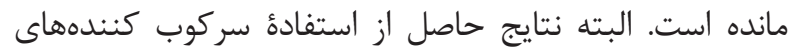

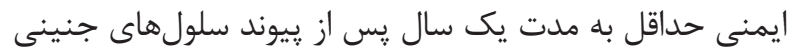

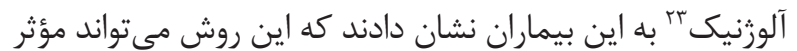
باشد وليكن نياز به بررسى بيشترى داردان

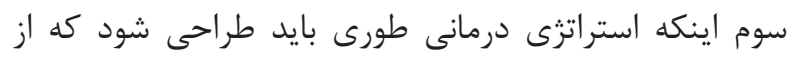
بروز اثرات معكوس جلوكيرى نمايد. در واقع بايد مطالعات شاتي

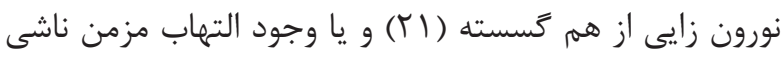

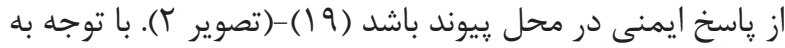

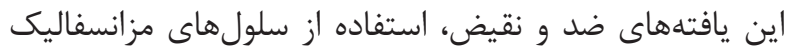

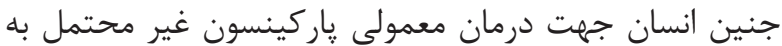

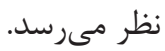

به منظور برطرف نمودن اين مشكل، محققين با انجام مطالعات

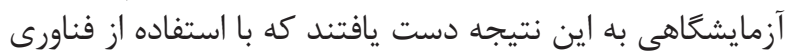

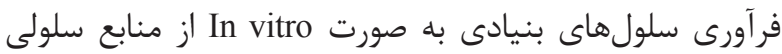

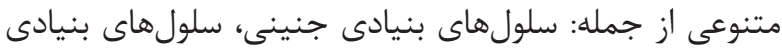

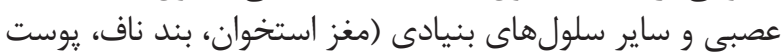

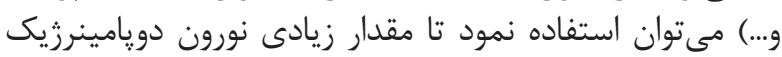

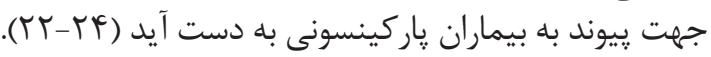

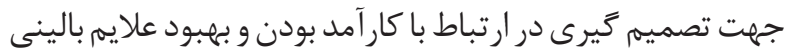

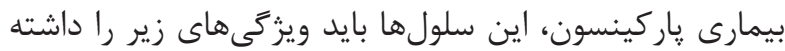

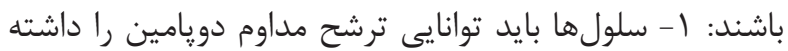

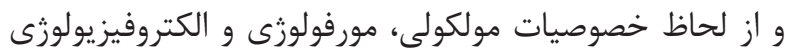

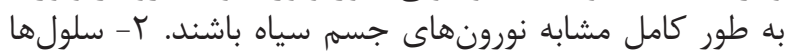

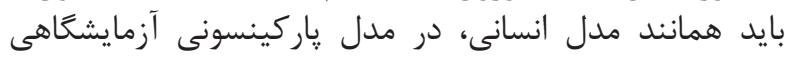

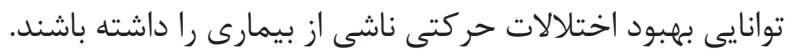

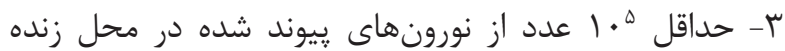

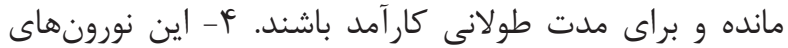

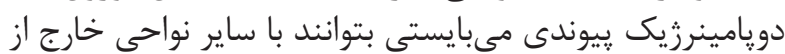
جسم مخطط ارتباط برقرار كنند.

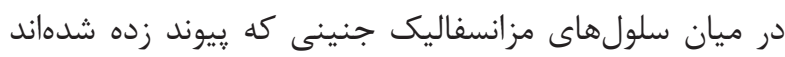

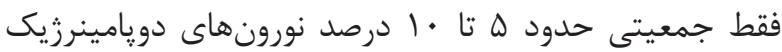

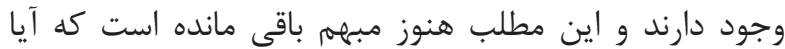

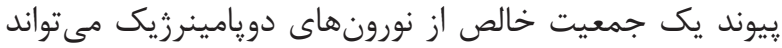

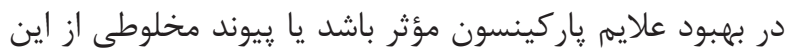

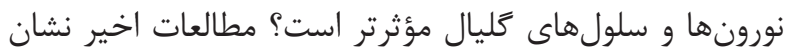

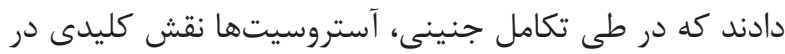

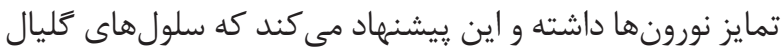

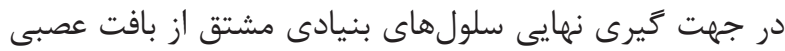

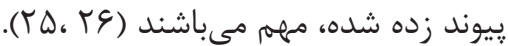

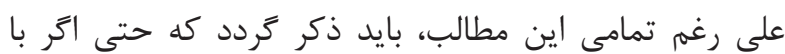

${ }^{23}$ Allogenic 
است. بنابراين آنها به دنبال يافتن راهى هستند تا روش درمانى

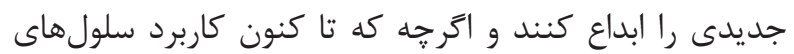

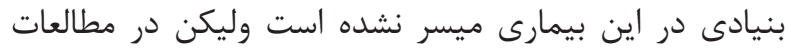

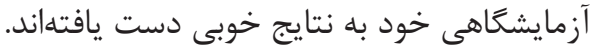

به تازكى Blurton- Jones و همكاران در مطالعهاى نشان

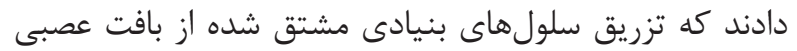

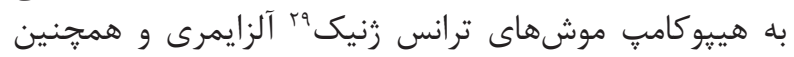

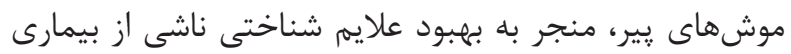

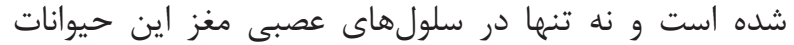

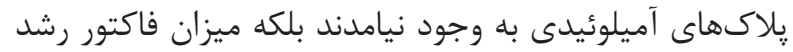

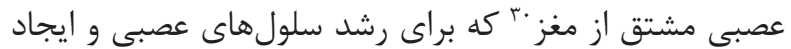

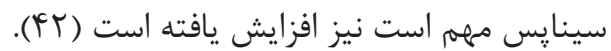

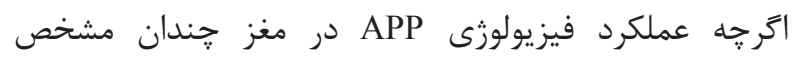

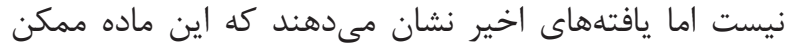

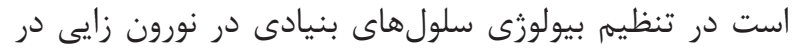

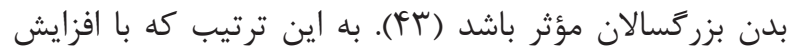

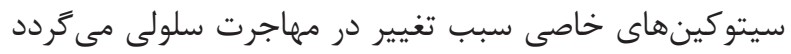

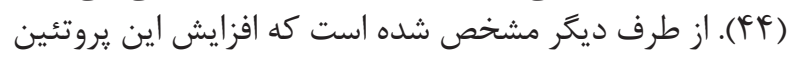

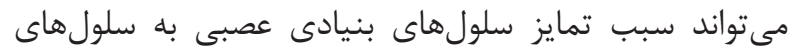

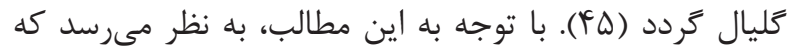

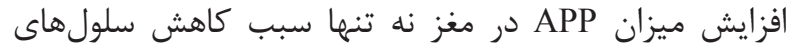

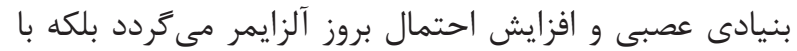

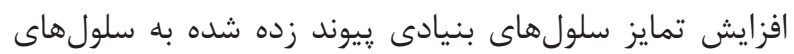

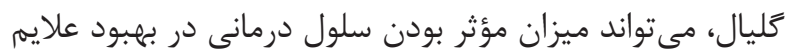

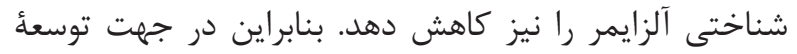

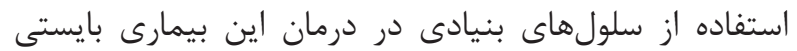
عملكرد APP در نظر گرفته شود.

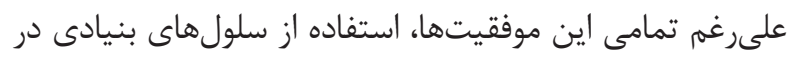

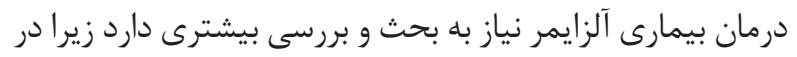

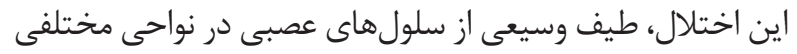

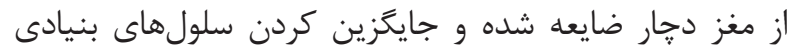

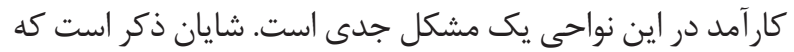

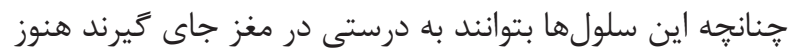

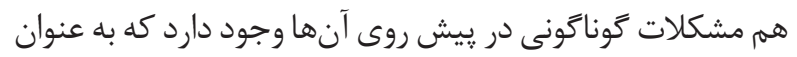

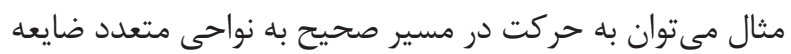

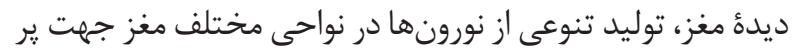

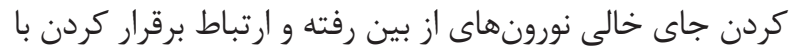
نورونهاى مجاور به طور صحيح اشاره نمود.

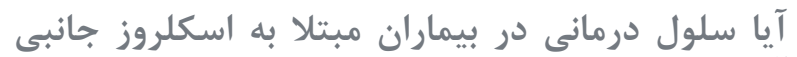

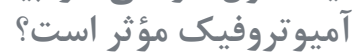

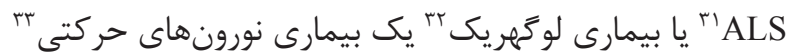

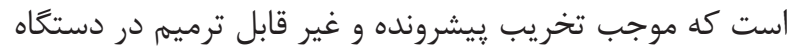

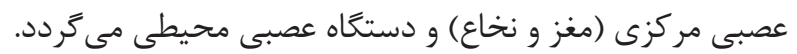

\footnotetext{
${ }^{24}$ Dementia

${ }^{25}$ Amyloid precursor protein (APP)

${ }^{26}$ Amyloid- $\beta$ peptide

${ }^{27} \mathrm{~N}$-Methyl-D-aspartate (NMDA)

${ }^{28}$ Memantine Hydrochloride
}

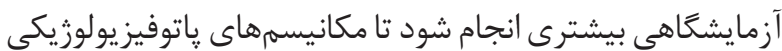

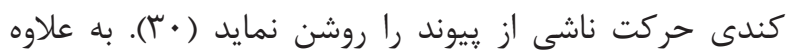

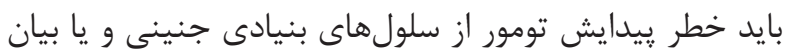

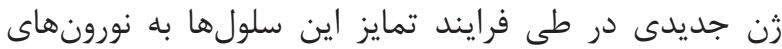
دويامينرزيك نيز در نظر گرفته شودي

در يك مطالعُ آزمايشكاهى، ييوند سلولهاى بنيادى جنهين

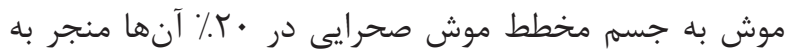

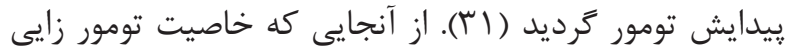

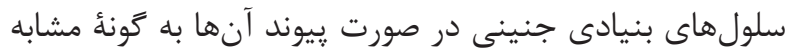

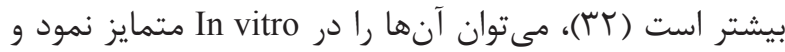

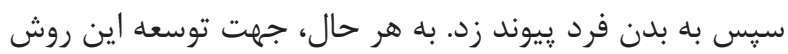

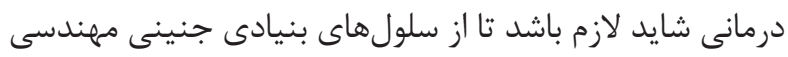

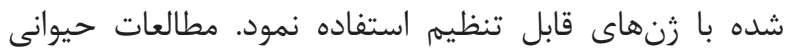

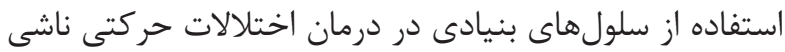

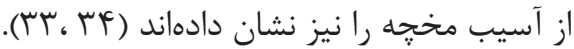

آيا سلول درمانى در بيماران مبتلا به بيمارى آلزايمر مؤثر است؟ كإن

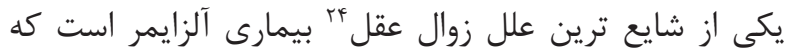

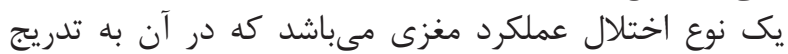

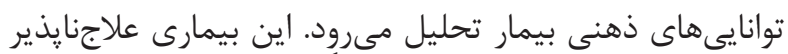

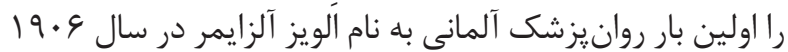

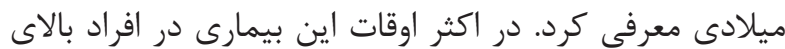

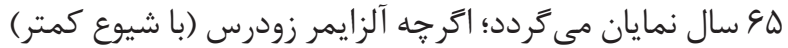

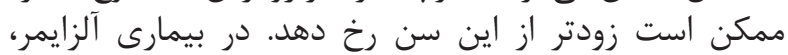

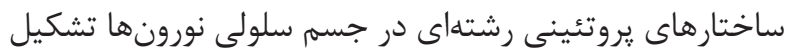

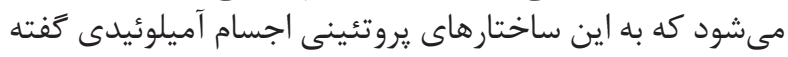

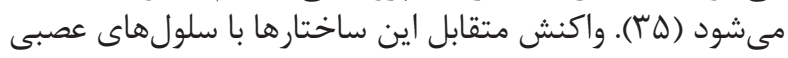
سبب از دست رفتن آنها مى مَردد.

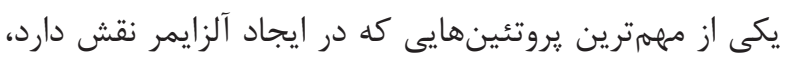

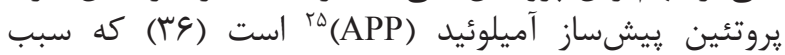

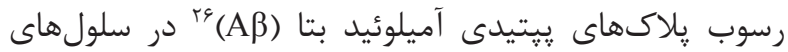

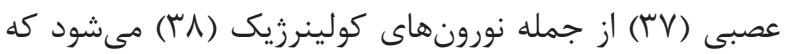

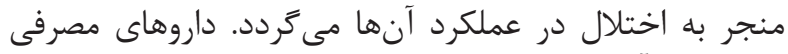

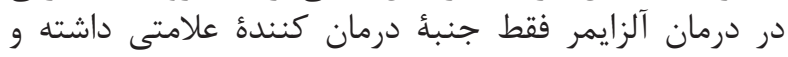

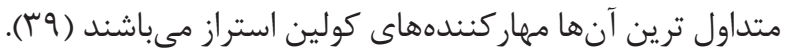

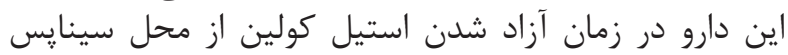

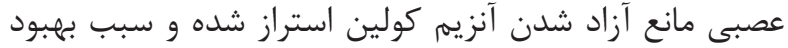

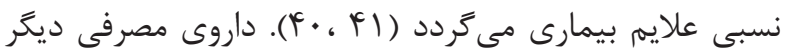

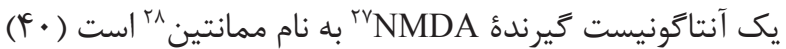

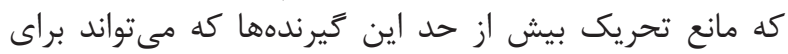

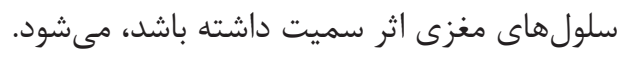

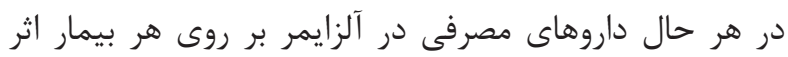

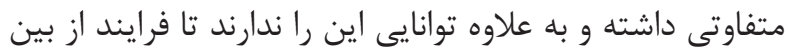

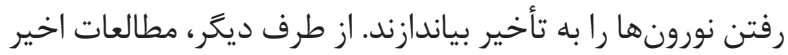

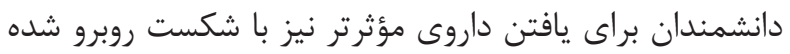

\footnotetext{
${ }^{29}$ Transgenic

${ }^{30}$ Brain-derived neurotrophic factor

${ }^{31}$ Amyotrophic lateral sclerosis (ALS)

${ }^{32}$ Lou Gehrig's disease

${ }^{33}$ Motor neuron disease (MND)
} 
با سابقهُ فاميلى بيمارى ALS نورونهاى حركتى توليد كنند

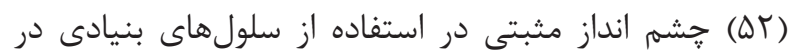

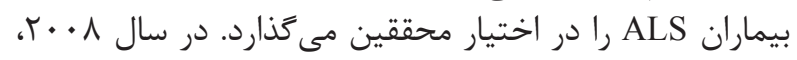
Mazzini

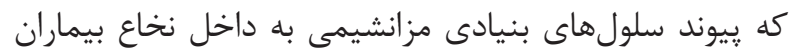

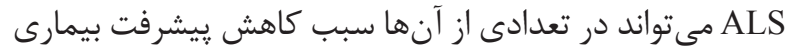

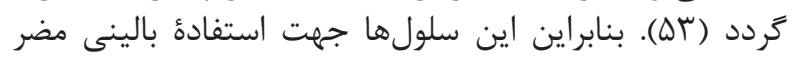

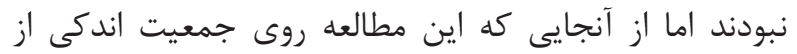

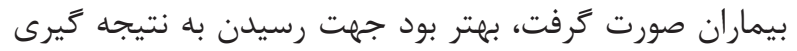

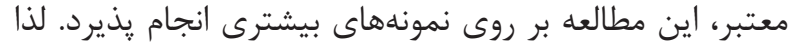

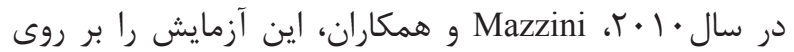

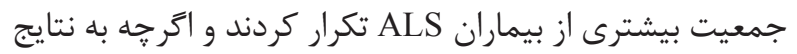

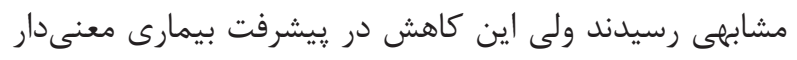

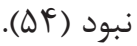

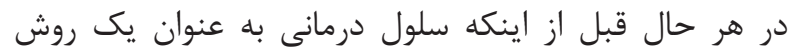

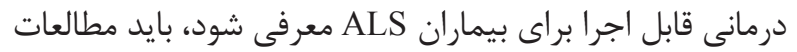

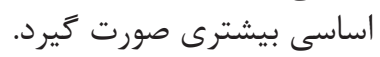

آيا سلول درمانى در بيماران مبتلا به اسكلروز منتشر صورد

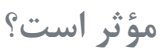

اسكلروز منتشر يا فلج جندكانه وَّيك بيمارى التهابى خود

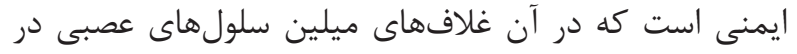
مغز و نخاع آسيب مى بينند (

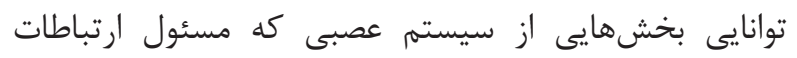

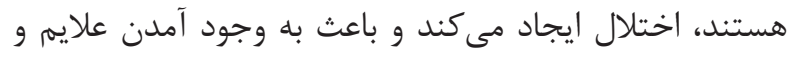

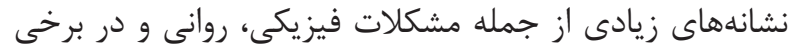

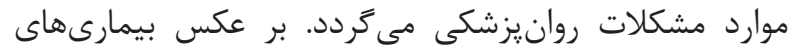

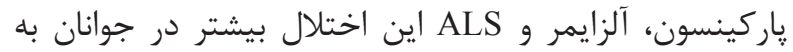

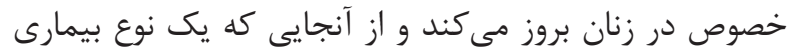

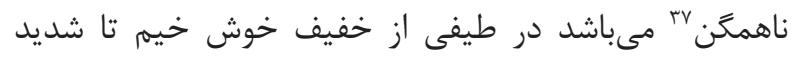

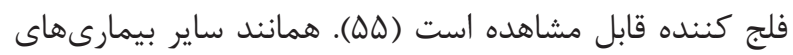

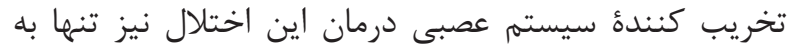

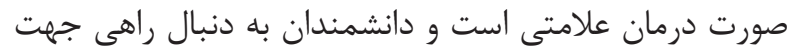
جايكزينى آن به سلول درمانى روى آوردند.

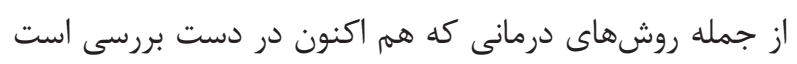

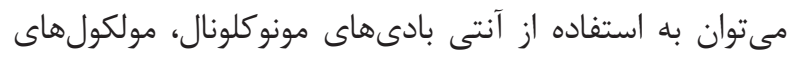

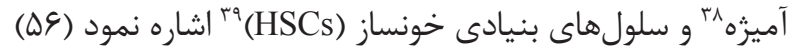

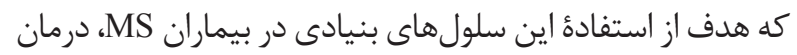

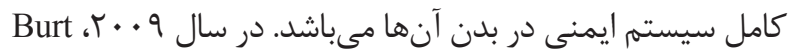

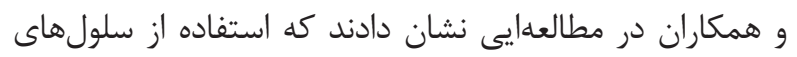

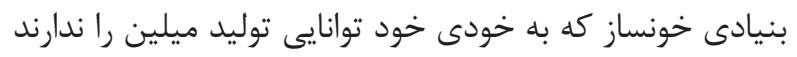

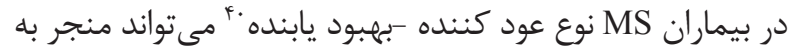

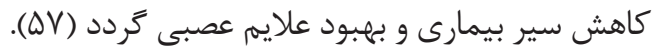
در مطالعهاى، Aharonowiz و همكاران مشخص كردند بيوند

\footnotetext{
${ }^{34}$ Microgliosis

${ }^{35}$ Induced pluripotent stem cells

${ }^{36}$ Encephalomyelitis disseminate or multiple sclerosis (MS)

${ }^{37}$ Heterogeneous
}

اين بيمارى شايع ترين بيمارى نورونهاى حركتى مى بـاشد كه

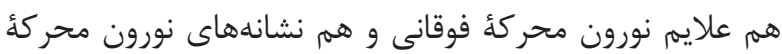

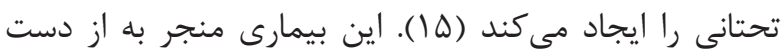

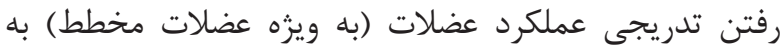

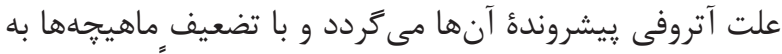

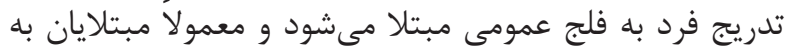

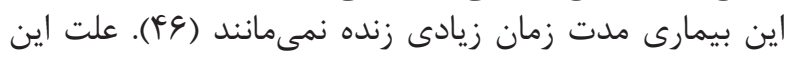
بيمارى تاكنون نامشخص مانده است.

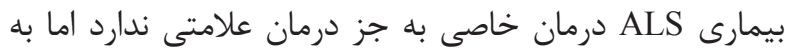

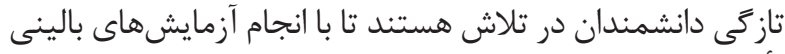

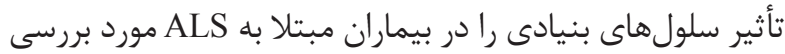

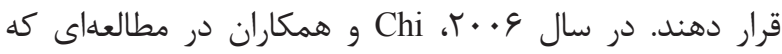

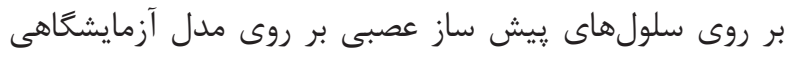

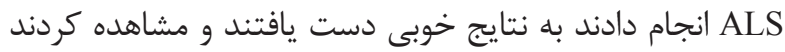

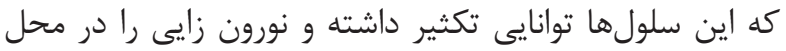

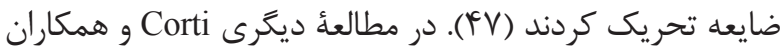

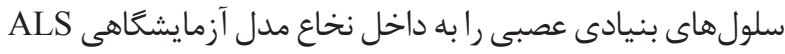

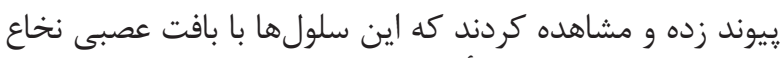

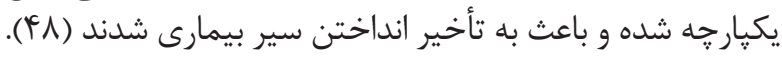

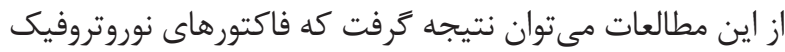

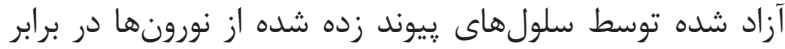
ضايعات ALS محافظت مى كنند.

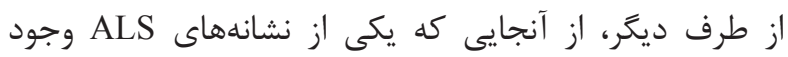

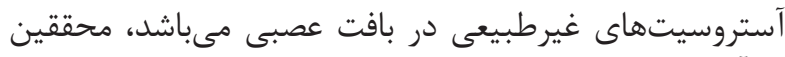

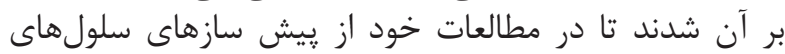

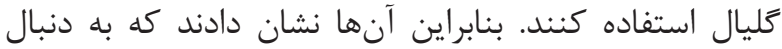

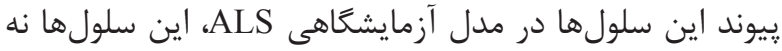

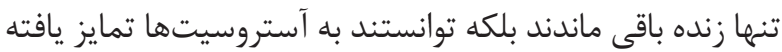

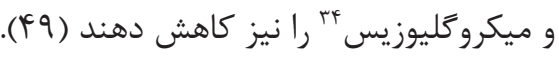

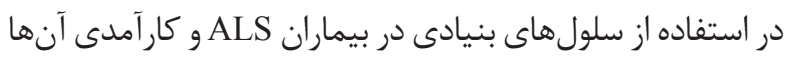

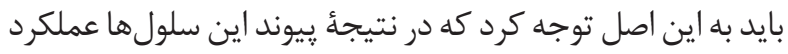

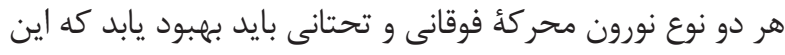

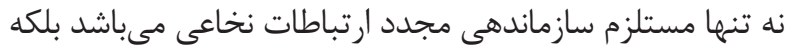

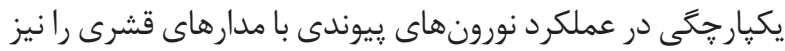

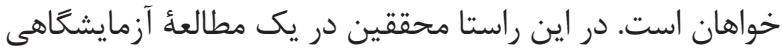

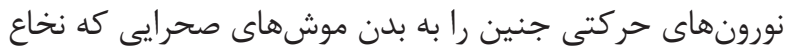

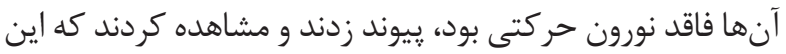

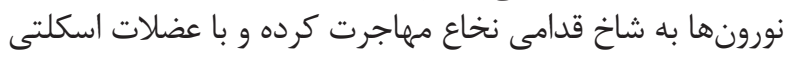

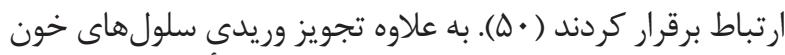

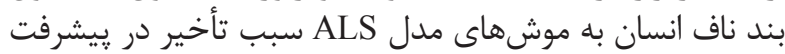

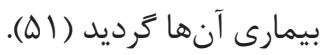

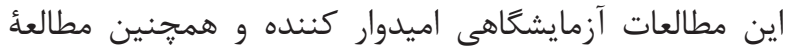

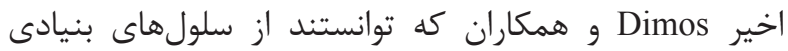

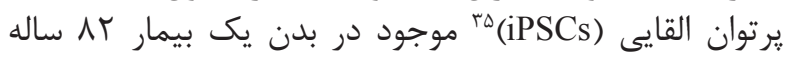

\footnotetext{
${ }^{38}$ Chimeric

${ }^{39}$ Hematopoietic stem cells (HSCs)

${ }^{40}$ Relapse-Remitting
} 
(צ (َ). در كل، نتايج حاصل از تمامى مطالعات بالينى يكسان

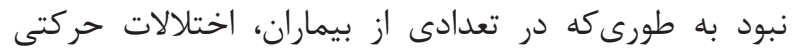

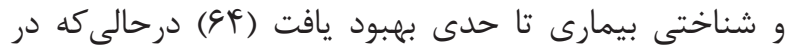

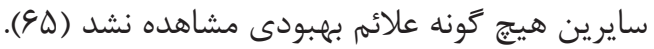

تكنولوزى استفاده از سلولهاى بنيادى در اين بيمارى توانسته

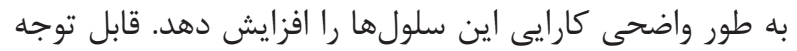

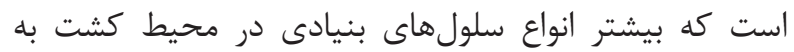

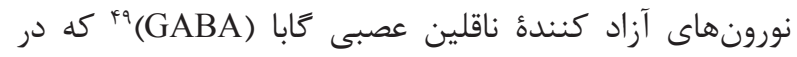

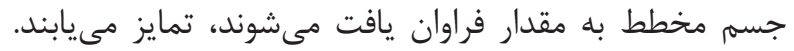

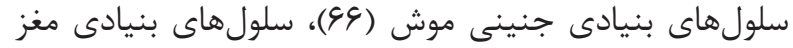

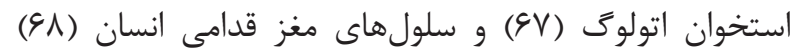

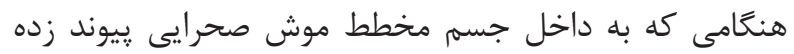
شدند به نورونهاى كابائرزيك له تمايز يافتند.

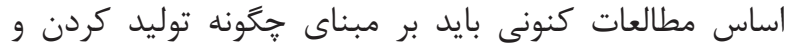

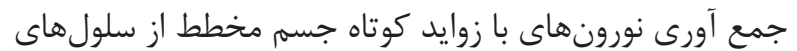

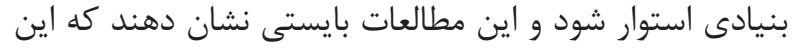

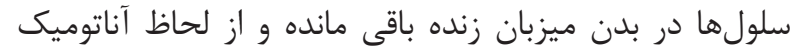

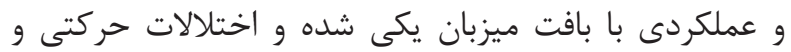

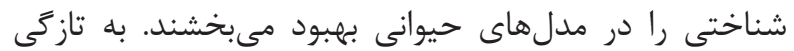

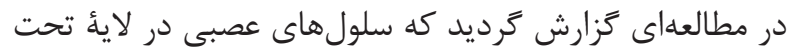

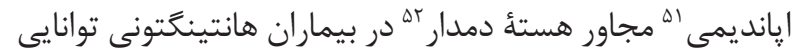

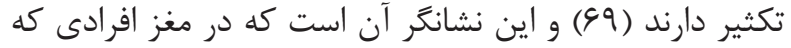

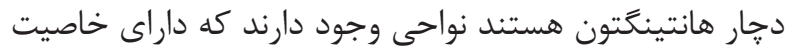

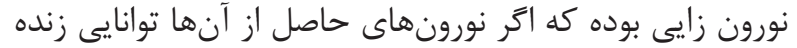

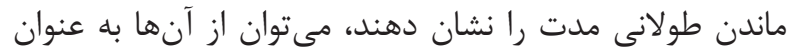

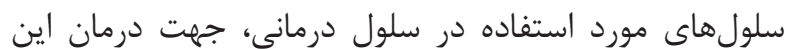

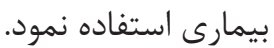

$$
\text { آيا سلول درمانى در سكتةُ مغزى كاربرد دارد؟ }
$$

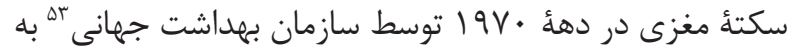

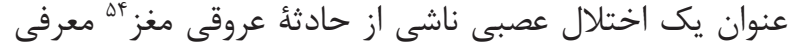

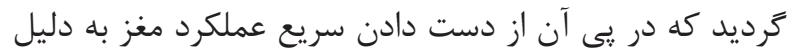

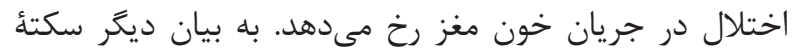

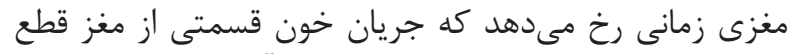

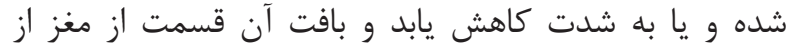

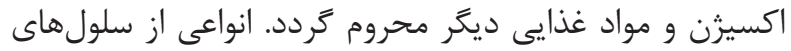

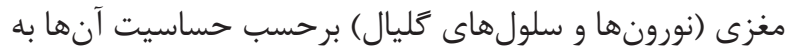

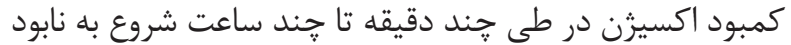

$$
\text { شدن و از بين رفتن مى كنند (V) (V)-(تصوير )َ). }
$$

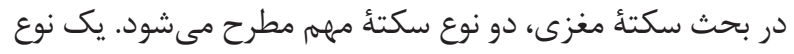

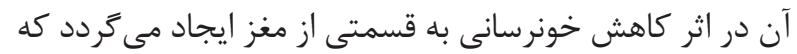

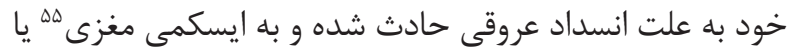

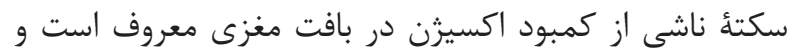

${ }^{41}$ Linage-restricted

${ }^{42}$ Huntington's disease

${ }^{43}$ George Huntington

${ }^{44}$ Chorea

${ }^{45}$ Medium spiny projection neurons

${ }^{46}$ Tetrabenazine

${ }^{47}$ Globus Pallidus

${ }^{48}$ Corticostriatopallidal circuitry
سلول بنيادى جنينى انسان به داخل بطنهاى مغزى موش،

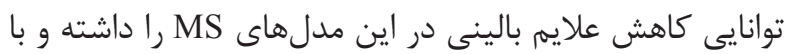

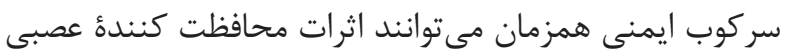

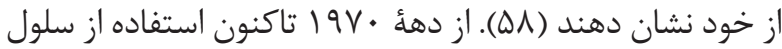

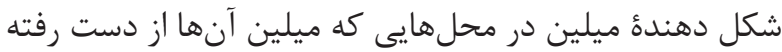

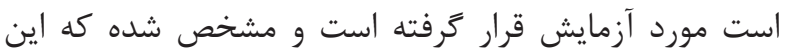

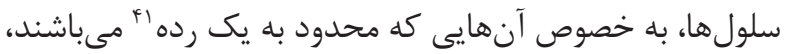

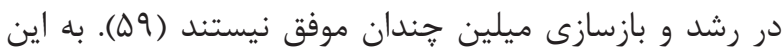

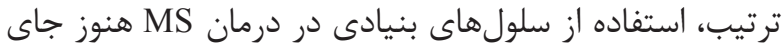
بحث و بررسى دارد.

آيا سلول درمانى در بيماران مبتلا به هانتينغَتون مؤثر

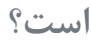

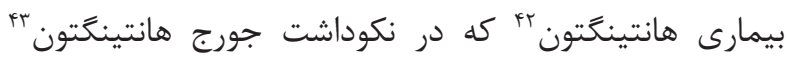

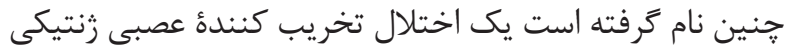

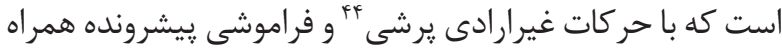

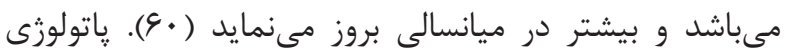

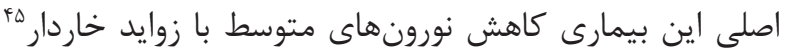

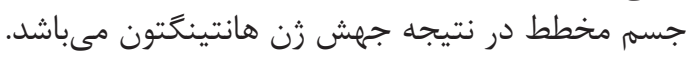

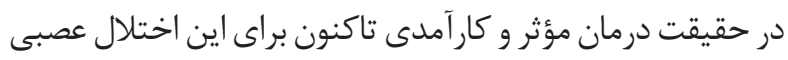

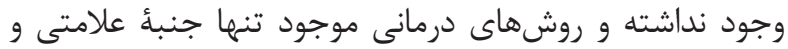

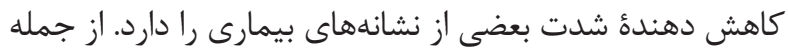

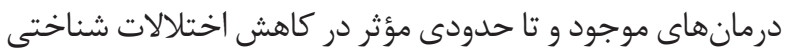

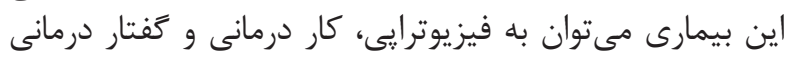

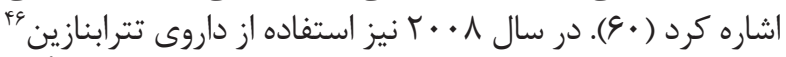

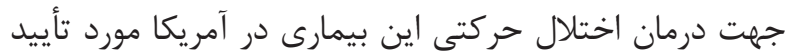

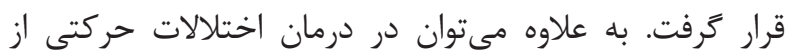

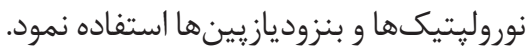

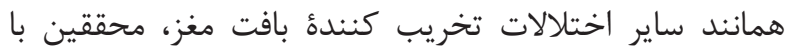

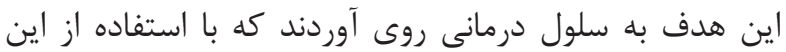

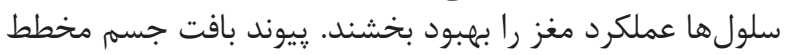

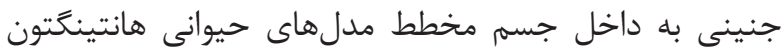

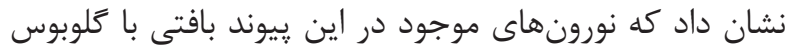

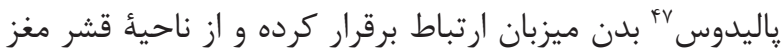

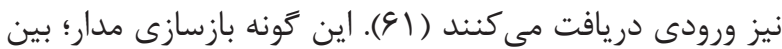

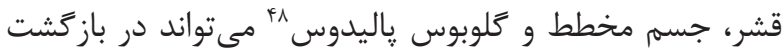

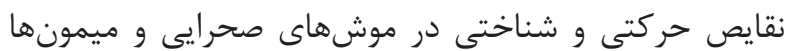

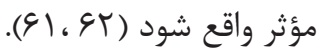

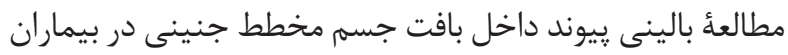

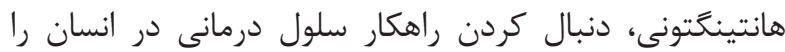

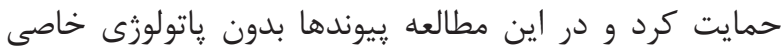

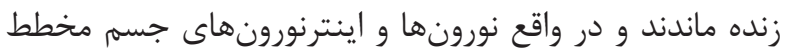
קيوند شده از ساير بخشهاى مغز بند بيماران، آوران دريافت كردند

${ }^{49} \gamma$-aminobutyric acid (GABA)

${ }^{50}$ GABAergic neurons

${ }^{51}$ Subependymal layer

${ }^{52}$ Caudate nucleus

${ }^{53}$ World Health Organization (WHO)

${ }^{54}$ Cerebrovascular accident

${ }^{55}$ Cerebral ischemia 


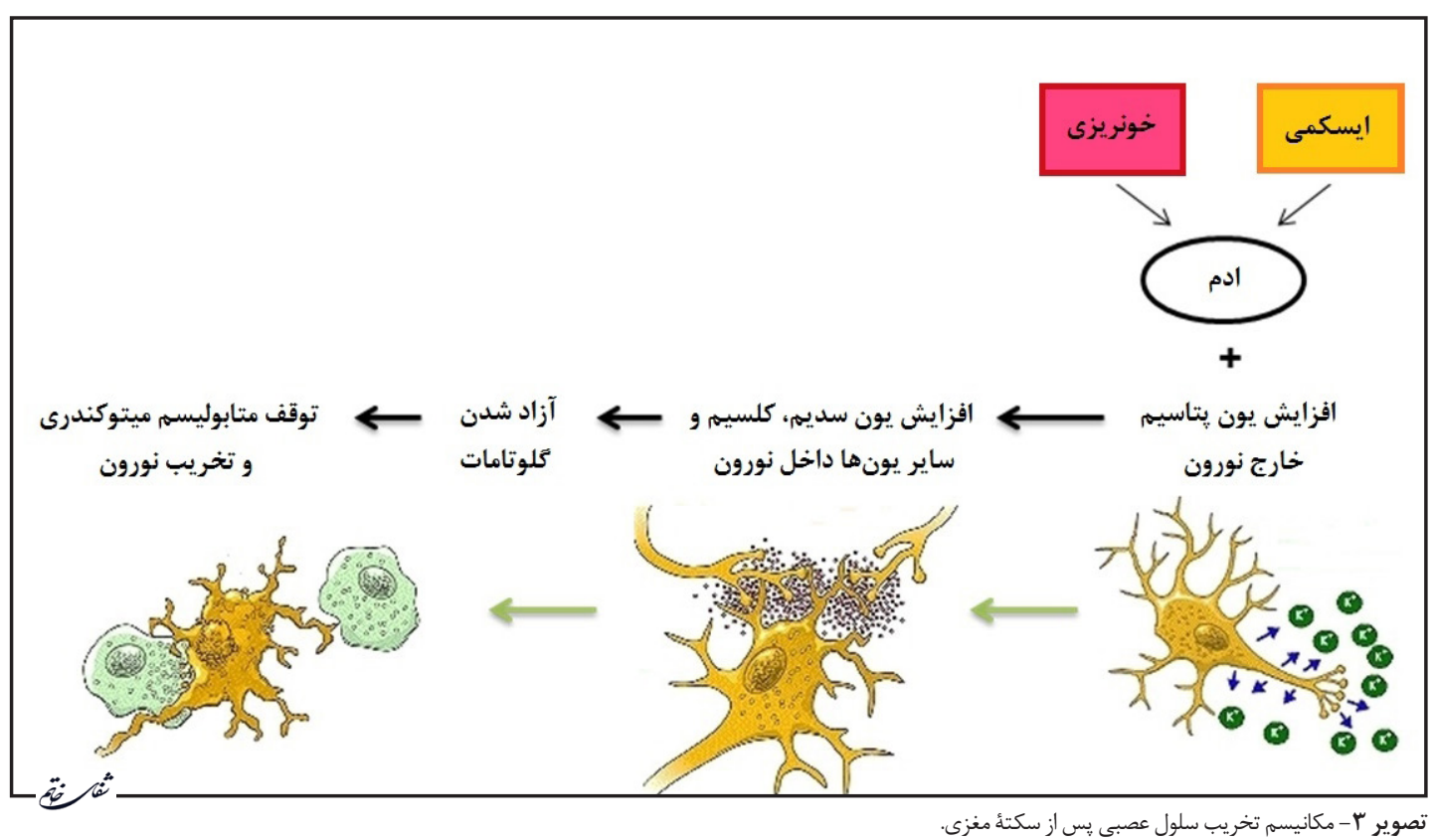

ممكن است نه تنها به روشهاى محافظتى عصبى كمك كنند

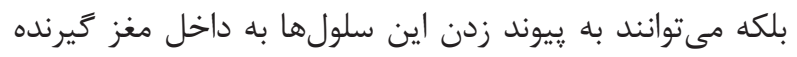

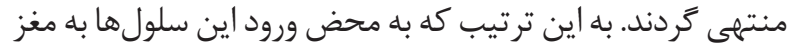

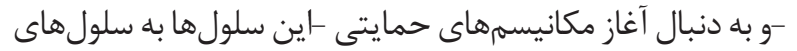

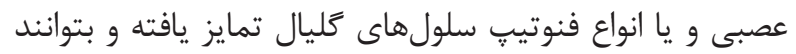

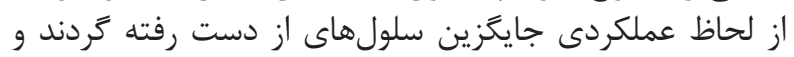

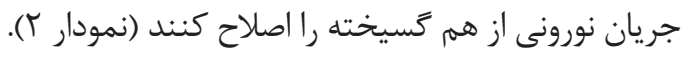
در ابتدا محققين مطالعات خود را بر روى مدلهاى حيوانى سكتئ
نوع ديخر سكته در اثر وجود مقادير زيادى خون در يك منطق إنه

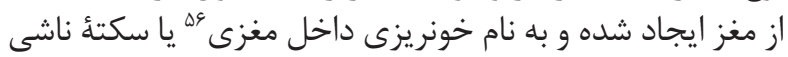

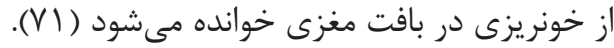
در حال حاضر درمان موجود براى اين بيمارى اساساً نتخهدارنده

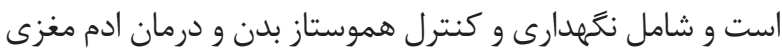

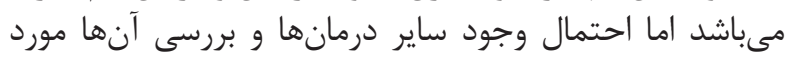

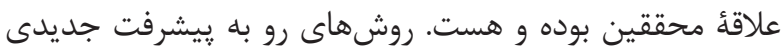

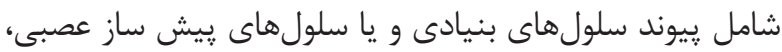

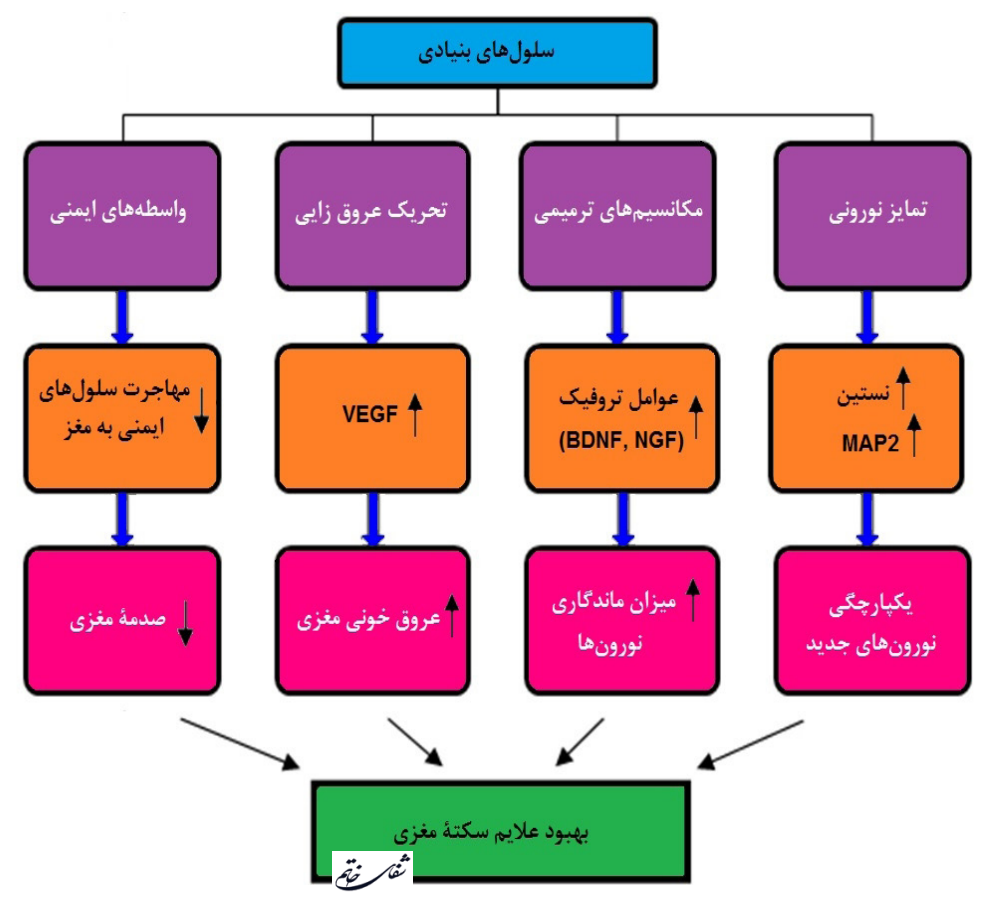

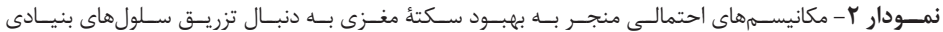

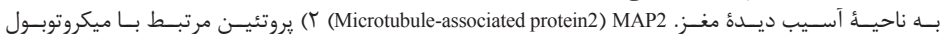

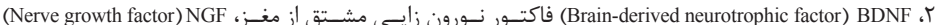

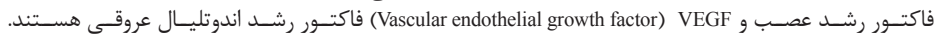

${ }^{56}$ Intracerebral hemorrhage (ICH) 
نورونهاى با زوايد خارى جسم مخطط را بيان مى كنند. بنابراين

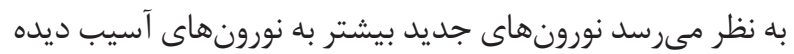

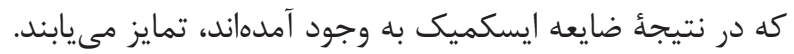

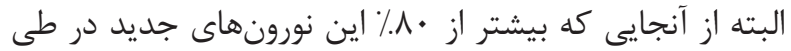

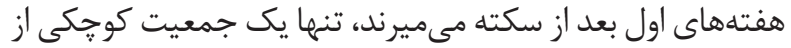

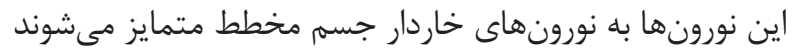

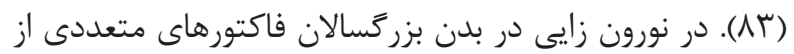

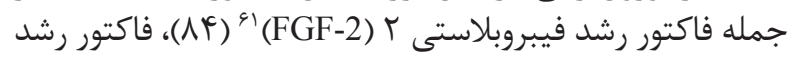

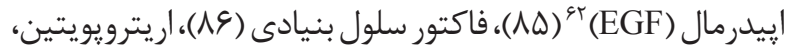

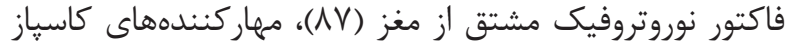

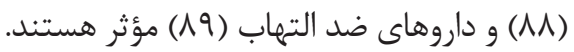

اينكه اين نورونها بعد از سكته مغزى كارآ آمد هستند يا نه، هنوز

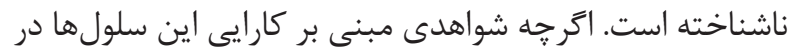

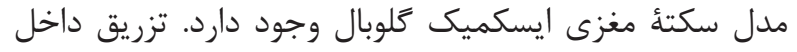

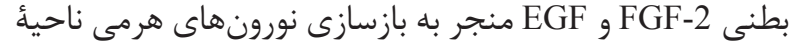

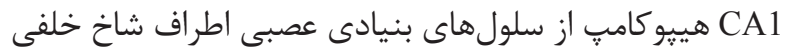

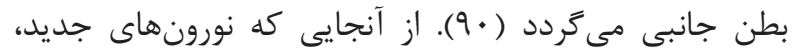

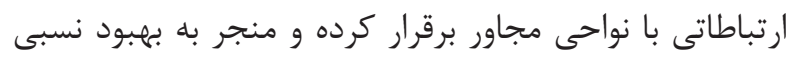

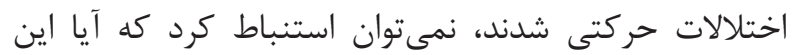

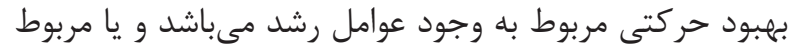

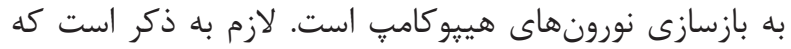

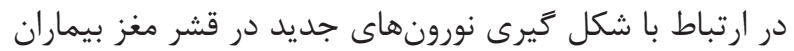

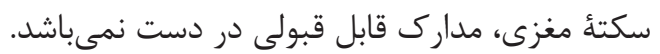

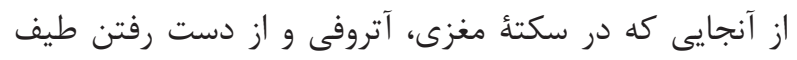

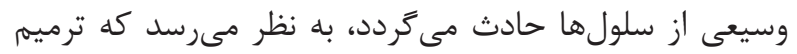

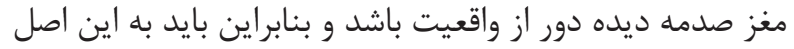

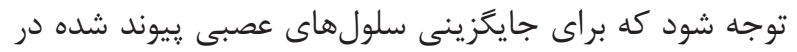

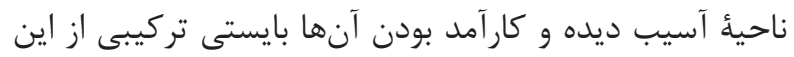

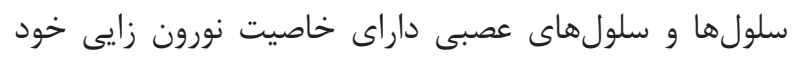

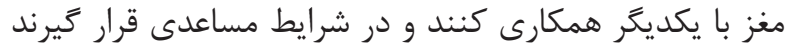

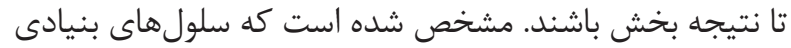

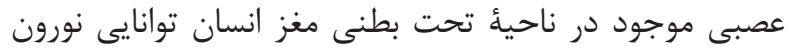

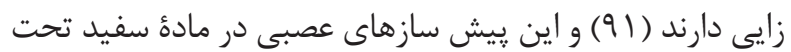

قشرى مغز انسان نيز يافت مىشوند (Y) (9)-(تصوير أ).

در بحث جايخيرى سلولهاى بيوندى و نورون زايى در سكتئ

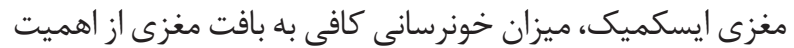

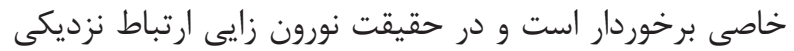

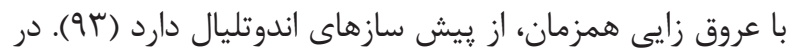

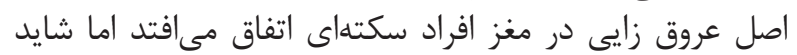

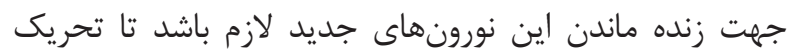

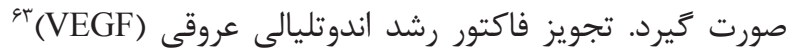

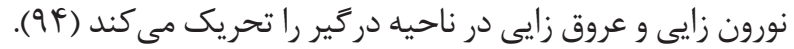

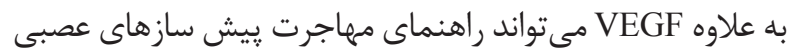

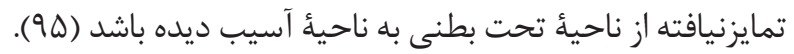

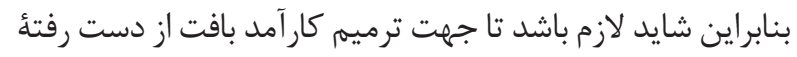

\footnotetext{
${ }^{57}$ Borlongan

${ }^{58}$ Jeong

${ }^{59}$ Human NTERA2

${ }^{60}$ Self-repair
}

مغزى ناشى از ايسكمى متمركز كردند و براى اولين بار در سال

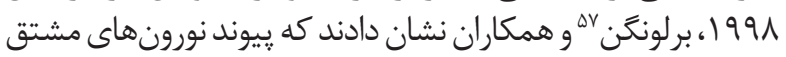

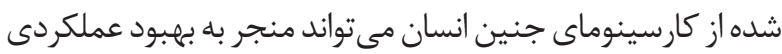

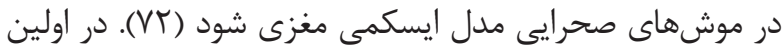

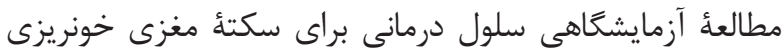

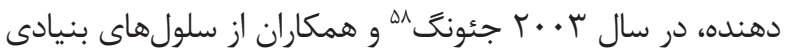

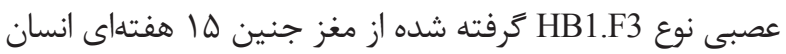

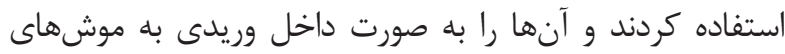

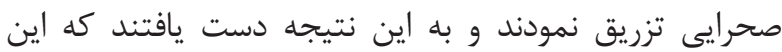

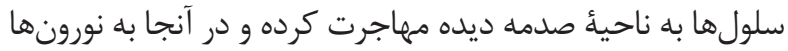

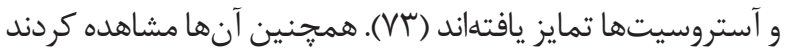

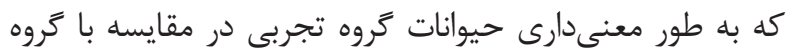

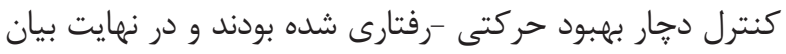

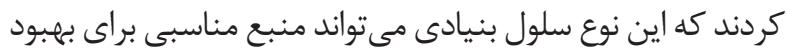
اختلالات نورولوزيك ناشى از اين نوع سكته مغزي بنى باشد.

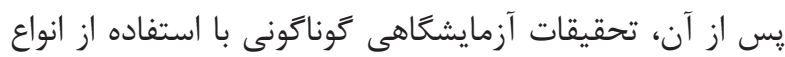

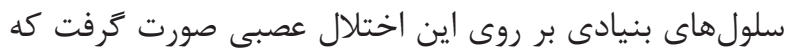

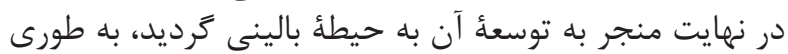

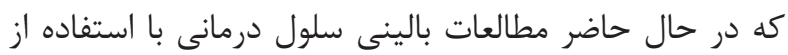

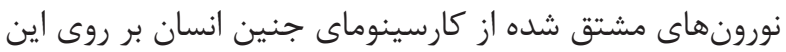

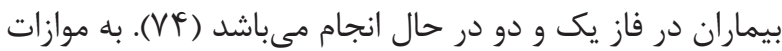

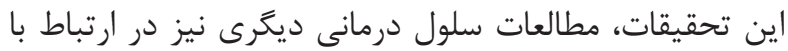

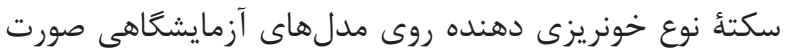

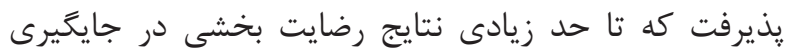

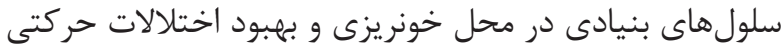

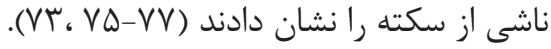

با اين وجود، هنوز نتايج متقاعد كنندهاى از جايكزينى سلول هاى

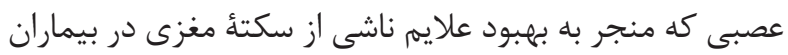

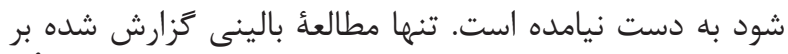

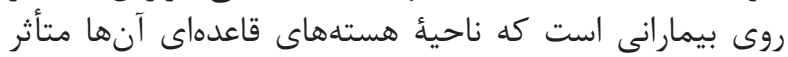

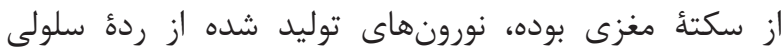

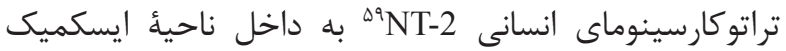

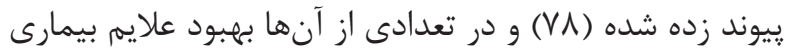

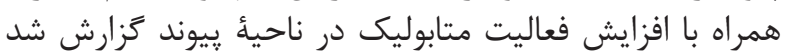

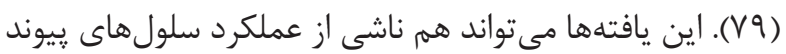

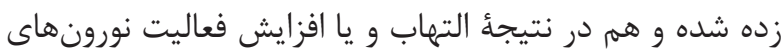

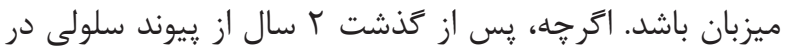

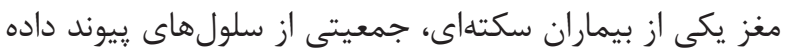

شده، نشانكر عصبى را بيان كردند (•).

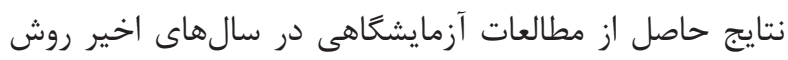

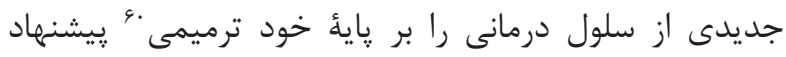

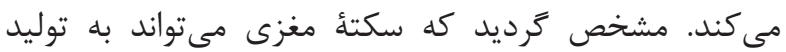

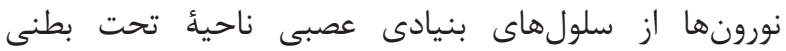

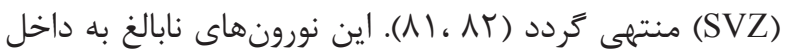

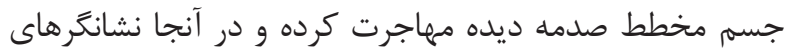

\footnotetext{
${ }^{61}$ Fibroblast growth factor 2

${ }^{62}$ Epidermal growth factor

${ }^{63}$ Vascular endothelial growth factor
} 


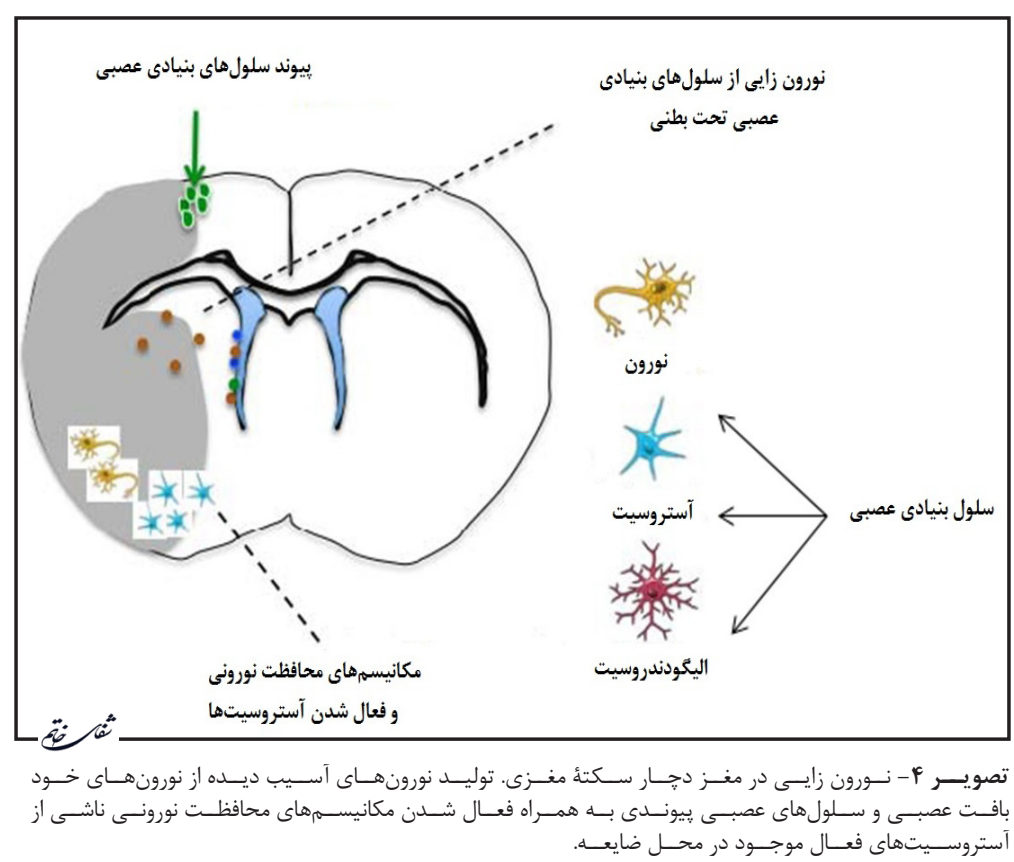

در مراحل اوليه بوده و هنوز جاى بِيشرفت دارد. بسيارى از باز

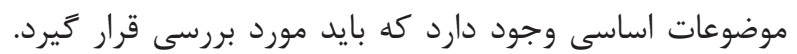

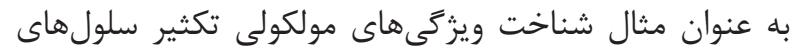

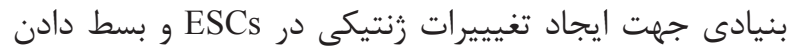

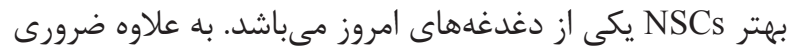

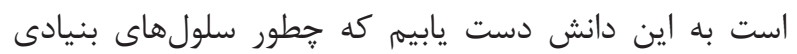

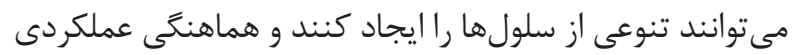

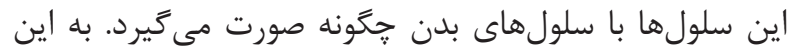

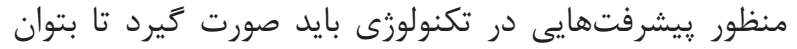

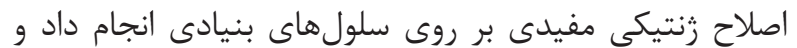

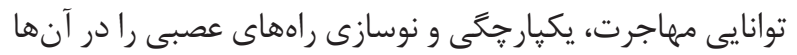

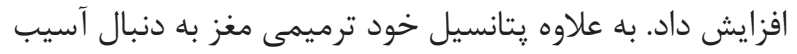

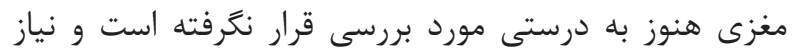

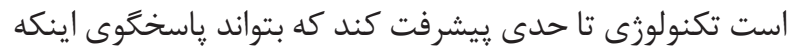

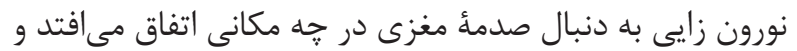
جه نوعى از سلولها توليد مىشوند، باشد.

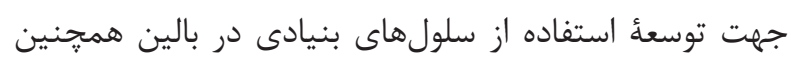

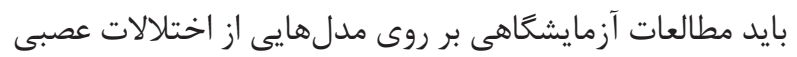

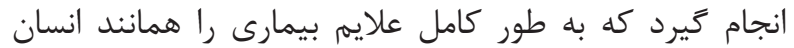

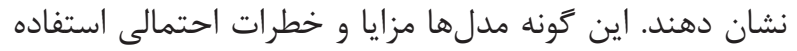

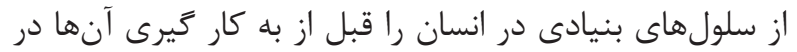

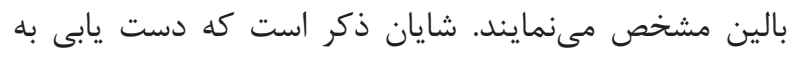

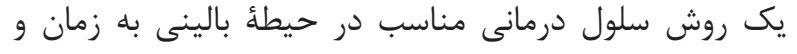

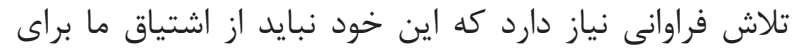

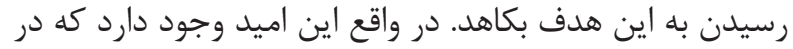

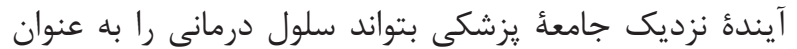

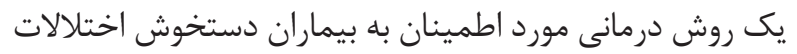

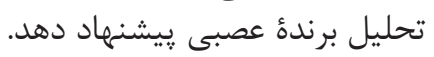

مغزى از سلول هاى بنيادى عصبى استفاده شود كه روى يايهاى از

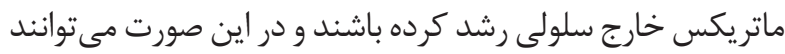

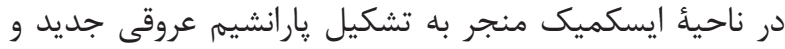
همجنين نورونها و سلولهاى كَليال شوند (9) (9).

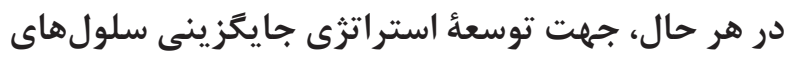

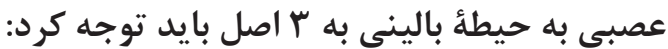

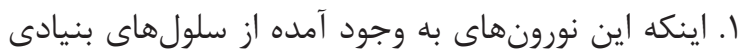

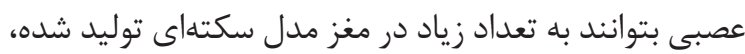

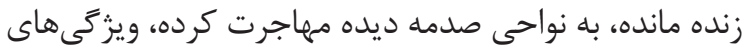

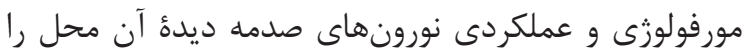

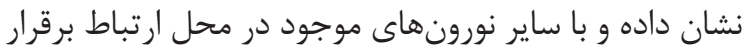

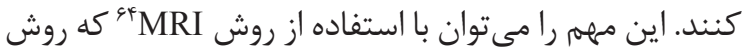

غيرتهاجمى قابل اطمينانى است، حاصل كرد (9V)

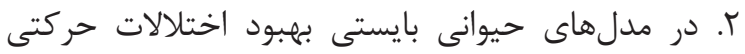

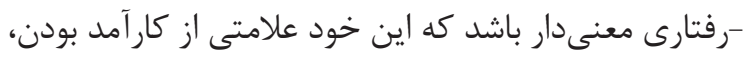

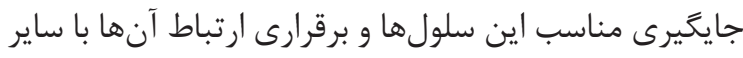

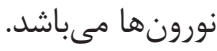

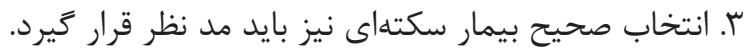

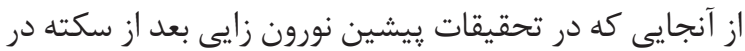

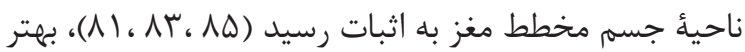

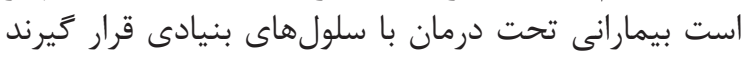

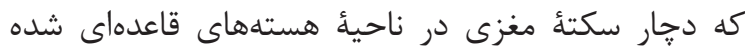

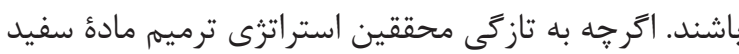

دجار آسيب را نيز در اين بيماران مطرح مي كنيند (91). نتيجه كيرى سلول درمانى به منظور درمان اختلالات تحليل برندة عصبى دهئو

${ }^{64}$ Magnetic resonance imaging (MRI)

${ }^{65}$ Neurodegenerative disorders 
1. Bliss T, Guzman R, Daadi M, Steinberg GK. Cell transplantation therapy for stroke. Stroke. 2007; 38(2 Suppl): 817-26.

2. Schouten JW, Fulp CT, Royo NC, Saatman KE, Watson DJ, Snyder EY, et al. A review and rationale for the use of cellular transplantation as a therapeutic strategy for traumatic brain injury. J Neurotrauma. 2004; 21(11): 1501-38.

3. Harris DT. Cord blood stem cells: a review of potential neurological applications .Stem Cell Rev. 2008;(4)4: 269-74.

4. Seghatoleslam M, Jalali M, Nikravesh MR, Hamidi Alamdari D, Hosseini M, Fazel A. Intravenous administration of human umbilical cord bloodmononuclear cells dose-dependently relieve neurologic deficits in rat intracerebral hemorrhage model. Ann Anat. 2013; 195(1): 39-49.

5. Ormerod BK, Palmer TD, Caldwell MA. Neurodegeneration and cell replacement. Philos Trans R Soc Lond B Biol Sci. 2008; 363(1489): 153-70.

6. Broderick JP, Brott T, Tomsick T, Huster G, Miller R. The risk of subarachnoid and intracerebral hemorrhages in blacks as compared with whites. N Engl J Med. 1992; 326(11): 733-6.

7. Kornblum HI. Introduction to neural stem cells. Stroke. 2007; 38(2 Suppl): 810-6.

8. Safford KM, Rice HE. Stem cell therapy for neurologic disorders: therapeutic potential of adipose-derived stem cells. Curr Drug Targets. 2005; 6(1): 57-62.

9. Sanberg PR, Willing AE, Garbuzova-Davis S, Saporta $\mathrm{S}$, Liu G, Sanberg CD, et al. Umbilical cord bloodderived stem cells and brain repair. Ann N Y Acad Sci. 2005; 1049: 67-83.

10. National Collaborating Centre for Chronic Conditions (UK). Parkinson's Disease: National Clinical Guideline for Diagnosis and Management in Primary and Secondary Care. Royal college of physicians of London. 2006. Available from: http://www.ncbi.nlm. nih.gov/books/NBK48523/.

11. Murrell W, Wetzig A, Donnellan M, Feron F, Burne $\mathrm{T}$, Meedeniya A, et al. Olfactory mucosa is a potential source for autologous stem cell therapy for Parkinson's disease. Stem Cells. 2008; 26(8): 2183-92.

12. Yasuhara T, Matsukawa N, Hara K, Yu G, Xu L,
Maki M, et al. Transplantation of human neural stem cells exerts neuroprotection in a rat model of Parkinson's disease. J Neurosci. 2006; 26(48): 12497-511.

13. Park HJ, Lee PH, Bang OY, Lee G, Ahn YH. Mesenchymal stem cells therapy exerts neuroprotection in a progressive animal model of Parkinson's disease. J Neurochem. 2008; 107(1): 141-51.

14. Cai J, Yang M, Poremsky E, Kidd S, Schneider JS, Iacovitti L. Dopaminergic neurons derived from human induced pluripotent stem cells survive and integrate into 6-OHDA-lesioned rats. Stem Cells Dev. 2010; 19(7): 1017-23.

15. Hideyama T, Yamashita T, Nishimoto Y, Suzuki T, Kwak S. Novel etiological and therapeutic strategies for neurodiseases: RNA editing enzyme abnormality in sporadic amyotrophic lateral sclerosis. J Pharmacol Sci. 2010; 113(1): 9-13.

16. Kordower JH, Freeman TB, Snow BJ, Vingerhoets FJ, Mufson EJ, Sanberg PR ,et al. Neuropathological evidence of graft survival and striatal reinnervation after the transplantation of fetal mesencephalic tissue in a patient with Parkinson's disease. N Engl J Med. 1995; 332(17): 1118-24.

17. Piccini P, Brooks DJ, Bjorklund A, Gunn RN, Grasby PM, Rimoldi O, et al. Dopamine release from nigral transplants visualized in vivo in a Parkinson's patient. Nat Neurosci. 1999; 2(12): 1137-40.

18. Piccini P, Lindvall O, Bjorklund A, Brundin P, Hagell $\mathrm{P}$, Ceravolo R, et al. Delayed recovery of movementrelated cortical function in Parkinson's disease after striatal dopaminergic grafts. Ann Neurol. 2000; 48(5): 689-95.

19. Olanow CW, Goetz CG, Kordower JH, Stoessl AJ, Sossi V, Brin MF, et al. A double-blind controlled trial of bilateral fetal nigral transplantation in Parkinson's disease. Ann Neurol. 2003; 54(3): 403-14.

20. Hagell P, Piccini P, Bjorklund A, Brundin P, Rehncrona S, Widner $\mathrm{H}$, et al. Dyskinesias following neural transplantation in Parkinson's disease. Nat Neurosci. 2002; 5(7): 627-8.

21. Ma Y, Feigin A, Dhawan V, Fukuda M, Shi Q, Greene $\mathrm{P}$, et al. Dyskinesia after fetal cell transplantation for parkinsonism: a PET study. Ann Neurol. 2002; 52(5): 628-34.

22. Draper JS, Smith K, Gokhale P, Moore HD, Maltby 
E, Johnson J, et al. Recurrent gain of chromosomes 17q and 12 in cultured human embryonic stem cells. Nat Biotechnol. 2004; 22(1): 53-4.

23. Amit M, Carpenter MK, Inokuma MS, Chiu CP, Harris CP, Waknitz MA, et al. Clonally derived human embryonic stem cell lines maintain pluripotency and proliferative potential for prolonged periods of culture. Dev Biol. 2000; 227(2): 271-8.

24. Roy NS, Nakano T, Keyoung HM, Windrem M, Rashbaum WK, Alonso ML, et al. Telomerase immortalization of neuronally restricted progenitor cells derived from the human fetal spinal cord. Nat Biotechnol. 2004; 22(3): 297-305.

25. Song H, Stevens CF, Gage FH. Astroglia induce neurogenesis from adult neural stem cells. Nature. 2002; 417(6884): 39-44.

26. Wagner J, Akerud P, Castro DS, Holm PC, Canals JM, Snyder EY, et al. Induction of a midbrain dopaminergic phenotype in Nurr1-overexpressing neural stem cells by type 1 astrocytes. Nat Biotechnol. 1999; 17(7): 653-9.

27. Shim JW, Koh HC, Chang MY, Roh E, Choi CY, $\mathrm{Oh} \mathrm{YJ}$, et al. Enhanced in vitro midbrain dopamine neuron differentiation, dopaminergic function, neurite outgrowth, and 1-methyl-4-phenylpyridium resistance in mouse embryonic stem cells overexpressing Bcl-XL. J Neurosci. 2004; 24(4): 843-52.

28. Kim JH, Auerbach JM, Rodriguez-Gomez JA, Velasco I, Gavin D, Lumelsky N, et al. Dopamine neurons derived from embryonic stem cells function in an animal model of Parkinson's disease. Nature. 2002; 418(6893): 50-6.

29. Moon LDF, Asher RA, Rhodes KE, Fawcett JW. Regeneration of CNS axons back to their target following treatment of adult rat brain with chondroitinase ABC. Nat Neurosci. 2001; 4(5): 465-6.

30. Steece-Collier K, Collier TJ, Danielson PD, Kurlan R, Yurek DM, Sladek JR Jr. Embryonic mesencephalic grafts increase levodopa-induced forelimb hyperkinesia in parkinsonian rats. Mov Disord. 2003; 18(12): 1442-54.

31. Bjorklund LM, Sanchez-Pernaute R, Chung S, Andersson T, Chen IY, McNaught KS, et al. Embryonic stem cells develop into functional dopaminergic neurons after transplantation in a Parkinson rat model. Proc Natl Acad Sci U S A. 2002; 99(4): 2344-9.

32. Erdo F, Buhrle C, Blunk J, Hoehn M, Xia Y, Fleischmann B, et al. Host-dependent tumorigenesis of embryonic stem cell transplantation in experimental stroke. J Cereb Blood Flow Metab. 2003; 23(7): 780-5.

33. Edalatmanesh MA, Bahrami AR, Hosseini E, Hosseini M, Khatamsaz S. Neuroprotective effects of mesenchymal stem cell transplantation in animal model of cerebellar degeneration. Neurol Res. 2011; 33(9): 913-20.

34. Edalatmanesh MA, Bahrami AR, Hosseini E, Hosseini M, Khatamsaz S. Bone marrow derived mesenchymal stem cell transplantation in cerebellar degeneration: a behavioral study. Behav Brain Res. 2011; 225(1): 63-70.

35. Alzheimer's Association2013 . Alzheimer's disease facts and figures. Alzheimers Dement. 2013;9(2): 208-45.

36. Waring SC, Rosenberg RN. Genome-wide association studies in Alzheimer disease. Arch Neurol. 2008; 65(3); 329-34.

37. Selkoe DJ. Translating cell biology into therapeutic advances in Alzheimer's disease. Nature. 1999; 399(6738 Suppl): A23-31.

38. Limke TL, Rao MS. Neural stem cells in aging and disease. J Cell Mol Med. 2002; 6(4): 475-96

39. Kadir A, Andreasen N, Almkvist O, Wall A, Forsberg A, Engler $\mathrm{H}$, et al. Effect of phenserine treatment on brain functional activity and amyloid in Alzheimer's disease. Ann Neurol. 2008; 63(5): 621-31.

40. Roberson ED, Mucke L. 100 years and counting: prospects for defeating Alzheimer's disease. Science. 2006; 314(5800): 781-4.

41. Mohammadpour T, Hosseini M, Naderi A, Karami R, Sadeghnia HR, Soukhtanloo M, et al. Protection against brain tissues oxidative damage as a possible mechanism for the beneficial effects of Rosa damascena hydroalcoholic extract on scopolamine induced memory impairment in rats. Nutr Neurosci. 2014.

42. Blurton-Jones M, Kitazawa M, Martinez-Coria H, Castello NA, Müller F-J, Loring JF, et al. Neural stem cells improve cognition via BDNF in a transgenic model of Alzheimer disease. Proc Natl Acad Sci USA. 2009; 106(32): 13594-9.

43. Sugaya K, Kwak YD, Ohmitsu O, Marutle A, Greig $\mathrm{NH}$, Choumrina E. Practical issues in stem cell therapy for Alzheimer's disease. Curr Alzheimer Res. 2007; 4(4): 370-7.

44. Vrotsos EG, Sugaya K. MCP-1-induced migration of NT2 neuroprogenitor cells involving APP signaling. 
Cell Mol Neurobiol. 2009; 29(3): 373-81.

45. Marutle A, Ohmitsu M, Nilbratt M, Greig NH, Nordberg A, Sugaya K. Modulation of human neural stem cell differentiation in Alzheimer (APP23) transgenic mice by phenserine. Proc Natl Acad Sci USA. 2007; 104(30): 12506-11.

46. Glass CK, Saijo K, Winner B, Marchetto MC, Gage FH. Mechanisms underlying inflammation in neurodegeneration. Cell. 2010; 140(6): 918-34.

47. Chi L, Ke Y, Luo C, Li B, Gozal D, Kalyanaraman $\mathrm{B}$, et al. Motor neuron degeneration promotes neural progenitor cell proliferation, migration, and neurogenesis in the spinal cords of amyotrophic lateral sclerosis mice. Stem Cells. 2006; 24(1): 34-43.

48. Corti S, Locatelli F, Papadimitriou D, Del Bo R, Nizzardo M, Nardini M, et al. Neural stem cells LewisX+ CXCR4+ modify disease progression in an amyotrophic lateral sclerosis model. Brain. 2007; 130(Pt 5): 1289-305.

49. Lepore AC, Rauck B, Dejea C, Pardo AC, Rao MS, Rothstein JD, et al. Focal transplantation-based astrocyte replacement is neuroprotective in a model of motor neuron disease. Nat Neurosci. 2008; 11(11): 1294-301.

50. Nogradi A, Vrbova G. Improved motor function of denervated rat hindlimb muscles induced by embryonic spinal cord grafts. Eur J Neurosci. 1996; 8(10): 2198-203.

51. Garbuzova-Davis S, Willing AE, Zigova T, Saporta $\mathrm{S}$, Justen EB, Lane JC, et al. Intravenous administration of human umbilical cord blood cells in a mouse model of amyotrophic lateral sclerosis: distribution, migration, and differentiation. J Hematother Stem Cell Res. 2003; 12(3): 255-70.

52. Dimos JT, Rodolfa KT, Niakan KK, Weisenthal LM, Mitsumoto H, Chung W, et al. Induced pluripotent stem cells generated from patients with ALS can be differentiated into motor neurons. Science. 2008; 321(5893): 1218-21.

53. Mazzini L, Mareschi K, Ferrero I, Vassallo E, Oliveri G, Nasuelli N, et al. Stem cell treatment in Amyotrophic Lateral Sclerosis. J Neurol Sci. 2008; 265(1-2): 78-83.

54. Mazzini L, Ferrero I, Luparello V, Rustichelli D, Gunetti M, Mareschi K, et al. Mesenchymal stem cell transplantation in amyotrophic lateral sclerosis: A Phase I clinical trial. Exp Neurol. 2010; 223(1): 229-37.

55. Weiner HL. The challenge of multiple sclerosis: how do we cure a chronic heterogeneous disease? Ann Neurol. 2009; 65(3): 239-48.

56. Harrison DM, Calabresi PA. Promising treatments of tomorrow for multiple sclerosis. Ann Indian Acad Neurol. 2009; 12(4): 283-90.

57. Burt RK, Loh Y, Cohen B, Stefoski D, Balabanov $\mathrm{R}$, Katsamakis G, et al. Autologous non-myeloablative haemopoietic stem cell transplantation in relapsingremitting multiple sclerosis: a phase I/II study. Lancet Neurol. 2009; 8(3): 244-53.

58. Aharonowiz M, Einstein O, Fainstein N, Lassmann H, Reubinoff B, Ben-Hur T. Neuroprotective effect of transplanted human embryonic stem cell-derived neural precursors in an animal model of multiple sclerosis. PLoS ONE. 2008; 3(9): e3145.

59. Pluchino S, Zanotti L, Brini E, Ferrari S, Martino G. Regeneration and repair in multiple sclerosis: the role of cell transplantation. Neurosci Lett. 2009; 456(3): 101-6.

60. Walker FO. Huntington's disease. Lancet. 2007; 369(9557): 218-28.

61. Dunnett SB, Nathwani F, Bjorklund A. The integration and function of striatal grafts. Prog Brain Res. 2000; 127: 345-80.

62. Kendall AL, Rayment FD, Torres EM, Baker HF, Ridley RM, Dunnett SB. Functional integration of striatal allografts in a primate model of Huntington's disease. Nat Med. 1998; 4(6): 727-9.

63. Freeman TB, Cicchetti F, Hauser RA, Deacon TW, Li XJ, Hersch SM, et al. Transplanted fetal striatum in Huntington's disease: phenotypic development and lack of pathology. Proc Natl Acad Sci USA. 2000; 97(25): 13877-82.

64. Bachoud-Levi AC, Remy P, Nguyen JP, Brugieres $\mathrm{P}$, Lefaucheur JP, Bourdet C, et al. Motor and cognitive improvements in patients with Huntington's disease after neural transplantation. Lancet. 2000; 356(9246): 1975-9.

65. Hauser RA, Furtado S, Cimino CR, Delgado H, Eichler S, Schwartz S, et al. Bilateral human fetal striatal transplantation in Huntington's disease. Neurology. 2002; 58(5): 687-95.

66. Dinsmore J, Ratliff J, Deacon T, Pakzaban P, Jacoby D, Galpern W, et al. Embryonic stem cells differentiated in vitro as a novel source of cells for transplantation. Cell Transplant. 1996; 5(2): 131-43. 
67. Lescaudron L, Unni D, Dunbar GL. Autologous adult bone marrow stem cell transplantation in an animal model of huntington's disease: behavioral and morphological outcomes. Int J Neurosci. 2003; 113(7): 945-56.

68. Fricker RA, Carpenter MK, Winkler C, Greco C, Gates MA, Bjorklund A. Site-specific migration and neuronal differentiation of human neural progenitor cells after transplantation in the adult rat brain. J Neurosci. 1999; 19(14): 5990-6005.

69. Curtis MA, Penney EB, Pearson AG, van Roon-Mom WM, Butterworth NJ, Dragunow M, et al. Increased cell proliferation and neurogenesis in the adult human Huntington's disease brain. Proc Natl Acad Sci USA. 2003; 100(15): 9023-7.

70. Donnan GA, Fisher M, Macleod M, Davis SM. Stroke. Lancet. 2008; 371(9624): 1612-23.

71. Sims NR, Muyderman H. Mitochondria, oxidative metabolism and cell death in stroke. Biochim Biophys Acta. 2010; 1802(1): 80-91.

72. Borlongan CV, Tajima Y, Trojanowski JQ, Lee VM, Sanberg PR. Transplantation of cryopreserved human embryonal carcinoma-derived neurons (NT2N cells) promotes functional recovery in ischemic rats. Exp Neurol. 1998; 149(2): 310-21.

73. Jeong SW, Chu K, Jung KH, Kim SU, Kim M, Roh JK. Human neural stem cell transplantation promotes functional recovery in rats with experimental intracerebral hemorrhage. Stroke. 2003; 34(9): 2258-63.

74. Becker DP, Verity MA, Povlishock J, Cheung M. Brain cellular injury and recovery--horizons for improving medical therapies in stroke and trauma. West J Med. 1988; 148(6): 670-84.

75. Mahmood A, Lu D, Wang L, Chopp M. Intracerebral transplantation of marrow stromal cells cultured with neurotrophic factors promotes functional recovery in adult rats subjected to traumatic brain injury. J Neurotrauma. 2002; 19(12): 1609-17.

76. Nan Z, Grande A, Sanberg CD, Sanberg PR, Low WC. Infusion of human umbilical cord blood ameliorates neurologic deficits in rats with hemorrhagic brain injury. Ann N Y Acad Sci. 2005; 1049: 84-96.

77. Seghatoleslam M, Jalali M, Nikravesh MR, Hosseini M, Hamidi Alamdari D, Fazel A. Therapeutic benefit of intravenous administration of human umbilical cord bloodmononuclear cells following intracerebral hemorrhage in rat. Iran J Basic Med Sci. 2012; 15(3): 860-72.
78. Kondziolka D, Wechsler L, Goldstein S, Meltzer C, Thulborn KR, Gebel J, et al. Transplantation of cultured human neuronal cells for patients with stroke. Neurology. 2000; 55(4): 565-9.

79. Meltzer CC, Kondziolka D, Villemagne VL, Wechsler L, Goldstein S, Thulborn KR, et al. Serial [18F] fluorodeoxyglucose positron emission tomography after human neuronal implantation for stroke. Neurosurgery. 2001; 49(3): 586-91.

80. Nelson PT, Kondziolka D, Wechsler L, Goldstein S, Gebel J, DeCesare S, et al. Clonal human (hNT) neuron grafts for stroke therapy: neuropathology in a patient 27 months after implantation. Am J Pathol. 2002; 160(4): 1201-6.

81. Parent JM, Vexler ZS, Gong C, Derugin N, Ferriero DM. Rat forebrain neurogenesis and striatal neuron replacement after focal stroke. Ann Neurol. 2002; 52(6): 802-13.

82. Jin K, Sun Y, Xie L, Peel A, Mao XO, Batteur S, et al. Directed migration of neuronal precursors into the ischemic cerebral cortex and striatum. Mol Cell Neurosci. 2003; 24(1): 171-89.

83. Arvidsson A, Collin T, Kirik D, Kokaia Z, Lindvall O. Neuronal replacement from endogenous precursors in the adult brain after stroke. Nat Med. 2002; 8(9): 963-70.

84. Jin K, Mao XO, Sun Y, Xie L, Greenberg DA. Stem cell factor stimulates neurogenesis in vitro and in vivo. $\mathrm{J}$ Clin Invest. 2002; 110(3): 311-9.

85. Teramoto T, Qiu J, Plumier JC, Moskowitz MA. EGF amplifies the replacement of parvalbumin-expressing striatal interneurons after ischemia. J Clin Invest. 2003; 111(8): 1125-32.

86. Shingo T, Sorokan ST, Shimazaki T, Weiss S. Erythropoietin regulates the in vitro and in vivo production of neuronal progenitors by mammalian forebrain neural stem cells. J Neurosci. 2001; 21(24): 9733-43.

87. Gustafsson E, Andsberg G, Darsalia V, Mohapel P, Mandel RJ, Kirik D, et al. Anterograde delivery of brain-derived neurotrophic factor to striatum via nigral transduction of recombinant adeno-associated virus increases neuronal death but promotes neurogenic response following stroke. Eur J Neurosci. 2003; 17(12): 2667-78.

88. Ekdahl CT, Mohapel P, Weber E, Bahr B, Blomgren $\mathrm{K}$, Lindvall O. Caspase-mediated death of newly formed 
neurons in the adult rat dentate gyrus following status epilepticus. Eur J Neurosci. 2002; 16(8): 1463-71.

89. Ekdahl CT, Claasen J-H, Bonde S, Kokaia Z, Lindvall O. Inflammation is detrimental for neurogenesis in adult brain. Proc Natl Acad Sci USA. 2003; 100(23): 13632-7.

90. Nakatomi H, Kuriu T, Okabe S, Yamamoto S, Hatano O, Kawahara N, et al. Regeneration of hippocampal pyramidal neurons after ischemic brain injury by recruitment of endogenous neural progenitors. Cell. 2002; 110(4): 429-41.

91. Sanai N, Tramontin AD, Quinones-Hinojosa A, Barbaro NM, Gupta N, Kunwar S, et al. Unique astrocyte ribbon in adult human brain contains neural stem cells but lacks chain migration. Nature. 2004; 427(6976): 740-4.

92. Nunes MC, Roy NS, Keyoung HM, Goodman RR, McKhann G 2nd, Jiang L, et al. Identification and isolation of multipotential neural progenitor cells from the subcortical white matter of the adult human brain. Nat Med. 2003; 9(4): 439-47.

93. Palmer TD, Willhoite AR, Gage FH. Vascular niche for adult hippocampal neurogenesis. J Comp Neurol.
2000; 425(4): 479-94.

94. Sun Y, Jin K, Xie L, Childs J, Mao XO, Logvinova $\mathrm{A}$, et al. VEGF-induced neuroprotection, neurogenesis, and angiogenesis after focal cerebral ischemia. J Clin Invest. 2003; 111(12): 1843-51.

95. Zhang H, Vutskits L, Pepper MS, Kiss JZ. VEGF is a chemoattractant for FGF-2-stimulated neural progenitors. J Cell Biol. 2003; 163(6): 1375-84.

96. Park KI, Teng YD, Snyder EY. The injured brain interacts reciprocally with neural stem cells supported by scaffolds to reconstitute lost tissue. Nat Biotech. 2002; 20(11): 1111-7.

97. Hoehn M, Kustermann E, Blunk J, Wiedermann D, Trapp T, Wecker S, et al. Monitoring of implanted stem cell migration in vivo: a highly resolved in vivo magnetic resonance imaging investigation of experimental stroke in rat. Proc Natl Acad Sci USA. 2002; 99(25): 16267-72.

98. Pluchino S, Quattrini A, Brambilla E, Gritti A, Salani $\mathrm{G}$, Dina $\mathrm{G}$, et al. Injection of adult neurospheres induces recovery in a chronic model of multiple sclerosis. Nature. 2003; 422(6933): 688-94. 